\title{
The Combined Effect of Enterprise Risk Management and Diversification on Property and Casualty Insurer Performance
}

\begin{abstract}
In a well-designed enterprise risk management (ERM) program, the firm integrates risk management into the strategic planning process, addressing strategic, financial, operational, and hazard risks under a single overarching process. This is particularly important to large financial firms, such as property and casualty $(\mathrm{P} \& \mathrm{C})$ insurers, which face a diverse set of risks. Using a sample of P\&C insurers with S\&P ERM quality ratings from 2006 to 2013, we find that the quality of a firm's ERM is a significant determinant of $\mathrm{P} \& \mathrm{C}$ insurer performance and that, for firms with high-quality ERM programs, product line diversification has a significant positive effect on performance.
\end{abstract}

Keywords: Enterprise Risk Management (ERM), Diversification, Property and Casualty, Insurance Company Performance

\section{Introduction}

As compared to traditional silo approaches to risk management, a holistic approach is believed to be more effective for firms with complex and interrelated risks, such as property and casualty (P\&C) insurers (Hoyt and Liebenberg, 2011; Ai et al., 2012). In a well-designed enterprise risk management (ERM) program, the firm integrates risk management into the strategic planning process, addressing strategic, financial, operational, and hazard risks under a single overarching process. A portfolio approach to risk management theoretically allows a firm to reduce inefficiencies and exploit natural hedges across the organization, thereby enhancing returns and value. In the last decade, in part due to regulatory requirements and rating agency criteria, nearly all insurers have adopted ERMbased approaches for dealing with the wide variety of risks they face (Beasley, Branson, and Hancock, 2012). However, the extent to which they have done so and the quality of their ERM programs differ from firm to firm (Grace et al., 2015). The academic literature has found ERM adoption to have positive effects on firm value and performance $]^{1}$ However, these conclusions have been based on short time series and have used

\footnotetext{
${ }^{1}$ For two recent reviews of the empirical literature on the determinants and value impact of ERM in the insurance industry, see Kraus and Lehner (2012) and Gatzert and Martin (2013).
} 
ERM-implementation proxies (e.g. announcements and management surveys) that do not distinguish ERM programs based on quality of implementation. This study adds to this growing literature by evaluating the effect of ERM quality on $\mathrm{P} \& \mathrm{C}$ insurer performance, while controlling for firm diversification strategy.

In theory, ERM should be most beneficial for large complex organizations. Therefore, consideration of the effects of ERM must necessarily take size and complexity into account. However, previous research has also shown that more diversified firms tend to suffer value and performance discounts relative to more focused competitors. Although large diverse organizations arguably benefit from scope economies and greater access to internal capital, they also may be less efficient due to complexity of coordination across units and potentially duplicative management and processes (Laeven and Levine, 2007). The most common explanation for the destruction of value for diversified firms is unwieldy operational costs (see, for example, Elango, Ma and Pope, 2008). These may include costs of coordinating across diverse units, incentive degradation (employees act in their own selfinterest, undermining broader firm efforts in value creation, despite incentive systems), and bureaucratic distortions (Nayyar, 1992). Additionally, it may be difficult and expensive for senior management of highly diversified firms to properly manage an increasingly dissimilar set of business operations (Jones and Hill, 1988). The empirical evidence in the insurance literature suggests that the costs of being diversified often outweigh the benefits, with many studies concluding that product line and/or geographic diversification result in reduced performance and/or value relative to more focused peers (Berger, Cummins, and Weiss, 2000; Elango, Ma and Pope, 2008; Liebenberg and Sommer, 2008; Berry-Stölzle, Hoyt, and Wende, 2013).

It is our hypothesis that one way in which high-quality ERM programs can add value to large complex organizations is through the establishment of metrics and decision processes that result in improved analysis of the benefits and costs associated with the corporate diversification strategy. There are obvious synergies from using a consistent risk management framework and process across the organization rather than in silos. Firms may benefit from improved operational efficiency, establishment of more effective incentive structures, and more appropriate allocation of capital, all of which are notable challenges for a diversified organization (Grace et al., 2015; Berry-Stozle and Xu, 2013). Shareholder value is arguably enhanced by optimizing the risk-return tradeoff in a portfolio context (Farrell and Gallagher, 2014).

Previous insurance research has identified positive value effects for ERM adoption and negative value effects for product line and geographic diversification. Our study con- 
tributes to this literature by identifying the combined performance and value effects of ERM and diversification for large P\&C insurers for the period 2006-2013, using a thirdparty ERM-quality assessment from Standard \& Poor's (S\&P). We find that diversification, when combined with high-quality ERM programs, can improve firm performance and help optimize shareholder outcomes as compared to silo approaches. Lastly, an additional contribution of this paper is to provide a detailed summary of the S\&P ERM rating criteria, cross-sectional characteristics of $\mathrm{P} \& \mathrm{C}$ insurer ratings, and the relationship of ERM ratings to financial strength ratings, which should be valuable information to researchers, investors, and regulators as ERM permeates corporate practices.

Because we limit our study to P\&C firms with S\&P ERM-quality ratings, our sample consists primarily of large multi-line firms (76 firms, of which only 3 were single-line in 2013). Although we cannot generalize the results to other firms with different characteristics, we believe that our results are economically significant because our sample represents $60 \%$ of the industry based on premiums written (over $75 \%$ of publicly-traded firms) and more than half of the industry by market capitalization. Furthermore, because larger firms are more likely to implement and benefit from ERM and to consider using a diversification strategy, the sample is fairly representative of the firms to which our research questions are most relevant.

The next section reviews the relevant theoretical and empirical literature on the performance effects of ERM and diversification, provides additional background on related trends for P\&C insurers, and explains the hypothesized ERM-diversification-performance relationship. We then identify the empirical models employed for testing this relationship, describe our sample, and present the empirical results.

\section{Background and Previous Literature}

Background and Literature Review on Enterprise Risk Management

A variety of factors have contributed to the widespread adoption of ERM, including enhanced concerns about systemic risks after the global financial crisis and improvements in technology related to risk quantification and tracking. ERM is uniquely different from traditional risk management approaches that have usually been reactive rather than proactive. Placement of risk management at higher levels of managerial responsibility, often the C-suite level, allows integration of risk decisions into fundamental corporate strate-

gies. Ultimately, the objectives of ERM are to protect and enhance stakeholder value (Hoyt and Liebenberg, 2011; Farrell and Gallagher, 2014; Ai, Brockett and Wang, 2015). 
Industry and rating agencies report anecdotal evidence that ERM softened the effect of the economic recession, increasing adopting firms' identification of and preparation for complex and interrelated risks (S\&P, 2010b).

Insurance industry stakeholders, including legislators, regulators, and rating agencies, have widely embraced ERM and taken actions to encourage adoption by firms. For example, the inclusion of ERM quality ratings in credit rating assessments by rating agencies, such as S\&P and A.M. Best, provides a strong incentive for ERM at rated firms. In addition, the NAIC's new regulatory standard Own Risk and Solvency Assessment (ORSA) is expected to provide a major push toward advancing the commitment to ERM as a value-enhancing strategy for U.S. insurers at all levels (NAIC, 2014). The Dodd-Frank Act (2010) creation of the Federal Insurance Office, charged with studying systemic risks posed by insurance products and firms, has put pressure on state legislators to adopt uniform standards that include mandated centralized risk management (Brown, 2013). In response to these changes, insurers and other financial firms are being proactive in adopting and implementing ERM. Based on a survey of 131 large financial institutions, Deloitte (2011) reports that 79 percent had ERM or equivalent centralized risk management programs in place in 2010, up from 59 percent in 2008. Similar rates of adoption were found in a 2011 survey of executives from other industries (Deloitte, 2012). The 2013 RIMS Enterprise Risk Management Survey found that 21 percent of respondents had fully integrated ERM across the organization and 42 percent had partially integrated ERM (RIMS, 2013). Whether the trend in ERM adoption is due to perceived valueenhancing effects by firm management or is merely a response to regulatory and rating agency policies is still a matter of debate.

There is an extensive literature on the value of risk management more generally. Possible benefits include reduced volatility for earnings and stock prices, reduced external capital costs, increased capital efficiency, operating flexibility, and cost reductions achieved through more efficient capture of synergies in risk management activities (See e.g. MacMinn, 1987; Meulbroek, 2002; Smithson and Simkins, 2005; Gamba and Triantis, 2013; Berry-Stölzle and Xu, 2013; Eckles, Hoyt, and Miller, 2014). Finance theory suggests that risk management has the potential to add value to diversified shareholders when it can reduce costs arising from market imperfections. Examples of market imperfections that can be addressed by risk management include taxes (Modigliani and Miller, 1963), agency costs (Jensen and Meckling, 1976), and external capital costs (Froot, Scharfstein, and Stein, 1993) ${ }^{2}$ The portfolio approach applied in ERM programs may also yield orga-

\footnotetext{
${ }^{2}$ For further discussion, see Grace et al. (2015) and Farrell and Gallagher (2014).
} 
nizational benefits such as increased risk awareness, synergistic cost reductions (Doherty, 2000; Nocco and Stulz, 2006) and improved capital allocation decisions (Myers and Reed, 2001).

The empirical literature on the value of ERM $\mathrm{S}^{3}$ has been hampered by lack of reliable and unbiased data on corporate risk management activities. Earlier ERM studies focus on the incidence and determinants of adoption and characteristics of firms with ERM programs (see e.g. Liebenberg and Hoyt, 2003; Kleffner, Lee, and McGannon, 2003; and Beasley, Clune and Hermanson, 2005). Not surprisingly, these studies find that size and complexity are major determinants of ERM adoption. Because an essential factor in the success of ERM implementation is that the program must be championed at a high level of management, several studies investigate whether the creation of a specialized managerial position, such as a Chief Risk Officer (CRO), is related to ERM adoption (Liebenberg and Hoyt, 2003; Beasley, Pagach and Warr, 2008; Pagach and Warr, 2011; RIMS, 2013). Although the appointment of a CRO may be a strong signal of firm commitment to ERM, Grace et al. (2015) point out that it may be only loosely correlated with implementation or effectiveness of an ERM program. Linking insurer financial data to a survey of risk management practices, they find that the existence of a primary reporting relationship from the risk manager to the C-Suite level of management (CEO or CFO) is an important factor because, otherwise, the risk manager may not have sufficient authority to implement necessary changes at an organizational level.

Given the increasing number of firms using ERM, academic interest is shifting from examining determinants of ERM adoption and CRO appointment to more interesting and timely questions related to the financial consequences, value effects, and/or efficiency effects of ERM (e.g. Gordon, Loeb, and Tseng 2009; Grace et al. 2015). The fact that most studies use announcements of CRO appointments or ERM adoption as proxies for ERM implementation without being able to distinguish firms based on quality of ERM (e.g. Hoyt and Liebenberg, 2011; Pagach and Warr, 2011; Berry-Stölzle and Xu, 2013) may explain the inconsistent results that have been reported in this literature. For example, Hoyt and Liebenberg (2011) simultaneously model the determinants of ERM adoption and the effect on firm value using Tobin's $Q$ as a proxy, and conclude that ERM adoption results in a 20 percent value premium. However, Pagach and Warr (2011) do not find a significant effect. A few studies use survey data on risk management activities as an ERM proxy (e.g. Kleffner, Lee, and McGannon, 2003; Beasley, Clune, and Hermanson,

\footnotetext{
${ }^{3}$ Although we briefly overview the literature in this section, for a more complete discussion and comparison of previous studies, see Gatzert and Martin (2013).
} 
2005; Farrell and Gallagher, 2014; Grace et al. 2015). For example, Grace et al. (2015) conclude that certain reported risk management characteristics, measured by responses to Tillinghast Towers Perrin ERM surveys from 2004 and 2006, result in improved cost and revenue efficiency. ${ }^{4}$ Their results are consistent with Farrell and Gallagher (2014) who use self-reported survey data from 2006-2011 and conclude that maturity of an ERM program and the degree of top-down executive engagement are positively related to firm value.

A conclusion of much of this prior literature is that ERM adoption and C-level oversight are value-enhancing to insurers. However, in the current environment, where nearly all insurers have taken these actions, estimation of value effects should control for the quality of the ERM programs. While survey data provides certain details that can be useful for analysis, they do not provide an independent quality assessment and thus share some common drawbacks with the self-reported announcement data used in several earlier ERM studies.

Until recently, it was not possible to analyze this issue due to the lack of unbiased data on ERM quality. However, the S\&P ERM-quality ratings offer the opportunity for additional insights into the value of ERM relative to subjective survey responses or selfreported public announcements related to ERM adoption or CRO appointments. This independent assessment of ERM-quality should improve performance model specification relative to previous studies. ERM-quality ratings have been used by rating agencies for several years in their financial strength assessments for some firms, but very few empirical studies have incorporated these measures thus far. Pooser (2012) examines the determinants of receiving an ERM quality rating by the S\&P in 2009 and 2010 and Baxter, et al. (2013) evaluate factors that are associated with higher ratings from 2006 to 2008. Size and complexity are found to be important factors in both studies. McShane, Nair, and Rustambeokov (2011) find a positive relationship between S\&P ERM quality and Tobin's Q for rated insurers in 2008. Because S\&P initially rated fewer firms, these studies cover small samples and short time series. Additionally, changes in the regulatory and risk management environment in recent years imply that insurers' risk management practices are likely to have evolved since then.

\footnotetext{
${ }^{4}$ Many other studies use frontier efficiency techniques to estimate insurer performance. See Cummins and Weiss (2014) for a summary. These measures have been shown to be positively related to traditional measures of firm performance. See e.g. Leverty and Grace (2010).
} 


\section{Literature on Diversification and Performance}

ERM is arguably of more benefit to diversified firms, in part because it may alleviate some of the negative value effects that have been documented in the literature. To the extent that product line and geographic diversification are key risk management strategies, it is interesting that many studies have found diversification to have a negative effect on performance and value, although the existence and the extent of the discount has been shown to differ by industry (Santalo and Becerra 2008). Theoretically, the benefits of insurer diversification are related to economies of scope, larger internal capital markets, potential for cross-selling of products, reduced costs of production, and more efficient governance structures. However, if not properly managed, these benefits may be offset by increased agency costs and less efficient allocation of capital among divisions of the firm 5 Most studies conclude that the net effect of diversification is negative for insurers. Evidence of decreasing returns to scale (Cummins and Xie, 2009) and negative value effects for acquirers (Shim, 2011) suggest that recent consolidation trends in the P\&C industry are explainable based on risk management objectives such as increased liquidity, improved efficiency, and capital allocation concerns ${ }^{6}$

The finding of a diversification discount is relatively robust to various measures of diversification and value as well as to different empirical methodologies. Insurer diversification has been measured in different ways in various studies, including: whether firms sell both $\mathrm{P} \& \mathrm{C}$ and Life and Health $(\mathrm{L} \& \mathrm{H})$ products versus specializing (Hoyt and Trieschmann, 1991); a dummy variable for single line vs. multi-line insurers (Liebenberg and Sommer 2008); the complement of the Herfindahl-Hirschman Index (HHI) across P\&C and L\&H (Tombs and Hoyt, 1994), across all 45 P\&C business lines, or across a reduced number of $\mathrm{P} \& \mathrm{C}$ business lines (with certain lines consolidated) (Elango, Ma, and Pope, 2008; Berry-Stölzle et al., 2011); and the complement of the HHI across geographies (Elango, Ma, and Pope, 2008).

Studies also differ in their choice of performance variables. For other industries, the effects of diversification have commonly been measured by reference to the impact on stock price or return. Because so few insurers are publicly traded, some studies have used return measures based on accounting or statutory values. Despite these issues, however, the diversification discount has been shown to be robust to the value measure choices,

\footnotetext{
${ }^{5}$ For a more complete review of this literature, see Berry-Stölzle et al. (2012) and Elango, Ma, and Pope (2008).

${ }^{6}$ For example, Powell and Sommer (2007) report on the prevalence of capital transfers among affiliated $\mathrm{P} \& \mathrm{C}$ insurers.
} 
with effects seen on stock returns (Hoyt and Trieschman, 1991), Tobin's Q and various accounting measures, such as Return on Assets (ROA) and Return on Equity (ROE) (Elango, Ma, and Pope, 2008; Liebenberg and Sommer, 2008). In a related study, Shim (2011) specifically looks at the value effects of diversification in mergers and acquisitions (M\&As). He finds that acquirers suffer a diversification discount and experience greater earnings volatility during and after the M\&As, perhaps as the result of increased frictions and agency problems.

Based on our review of the literature, the value effects of combined ERM and diversification strategies on $\mathrm{P} \& \mathrm{C}$ insurers are still indeterminate. Diversification is a strategic decision that should be based on careful evaluation of risks and rewards. Given the various potential benefits of ERM as previously discussed, firms with high quality ERM programs might be able to better capture the value-enhancing effects of the diversification decision, whereas those with ineffective and/or decentralized risk management might not. As an example, ERM might lead a given firm's management to a more diversified strategy because its analysis suggests that the firm has a unique ability to manage in diverse geographies or product lines, leading to competitive advantage and value creation. Another firm's management might come to the conclusion that a more focused approach is preferable because diversification imposes too many agency costs. Appropriate risk management strategies are designed and implemented in conjunction with the diversification strategy to maximize performance and value 7 In addition to differences in methodologies, sample periods, control variables, and measures of ERM and diversification, the previous literature has not examined these interacting effects. Furthermore, most ERM and diversification studies analyze data from years that precede the financial crisis, widespread adoption of ERM, and recent declines in $\mathrm{P} \& \mathrm{C}$ product line diversification. In the next section, we describe these recent trends in more detail as motivation for our empirical study of the combined effects of ERM and diversification.

\footnotetext{
${ }^{7}$ Compare, for example, two highly rated insurers with very different diversification strategies. The S\&P ERM report on USAA compliments the firm on its excellent ERM program and notes that: "Although USAA has a diverse product portfolio including life, personal lines, bank, and asset management, USAA has limited the risk by not engaging in products that increase its risk profile, and it exploits its position as a non-public company by having an adequate capital cushion." (S\&P, 2011) S\&P also praises GEICO's ERM program but notes that the firm's focus on personal auto is a "strength to the rating." (S\&P, 2009) These two examples show that Excellent/Strong ERM programs can be associated with very different diversification decisions, and both ERM and diversification are aspects of optimized corporate strategies.
} 


\section{Recent Trends in P\&C Diversification and ERM}

Two important trends in the $\mathrm{P} \& \mathrm{C}$ insurance industry that provide motivation for our research are declining product line diversification and widespread adoption of centralized risk management approaches.

\section{Declining Diversification}

Whereas other industries have continued the trend of the last decades toward diversification to achieve economies of scale and scope, P\&C insurers are becoming more focused by product line in recent years (Shim, 2011). We define geographic and business line diversification using the standard approach in the insurance literature. Business line diversification $\left(B L D I V_{k t}\right)$ and geographic diversification $\left(G E O D I V_{k t}\right)$ for firm $k$ in year $t$ are measured as the complement of the Herfindahl-Hirschman concentration Index. These are defined in Equations 1 and 2:

$$
\begin{gathered}
B L D I V_{k t}=1-\sum_{j=1}^{24}\left(\frac{D P W_{k j t}}{D P W_{k t}}\right)^{2} \\
G E O D I V_{k t}=1-\sum_{j=1}^{57}\left(\frac{D P W_{k j t}}{D P W_{k t}}\right)^{2}
\end{gathered}
$$

where $D P W_{k j t}$ is the direct premiums written for the business line $j$ (or geographic area j). Consistent with Berry-Stölzle et al. (2012), business line diversification considers premiums written across 24 lines of business 8 and the geographic diversification measure is based on direct premiums written across 57 geographic areas, as reported in the NAIC statutory accounting statements. The historical trends in average firm-level business line and geographic diversification from 2001 to 2013, not including single line firms and firms which operate in only one state, are illustrated in Figure 1.

During the period depicted in this graph, average BLDIV for multi-line firms declined from 0.49 to 0.44 , but over that same period, average GEODIV was virtually unchanged at

\footnotetext{
${ }^{8}$ Previous studies have defined concentration and diversification based on the full 43 lines reported on Schedule P of the NAIC financial reports (see e.g. Bajtelsmit and Bouzouita, 1998) or based on a smaller number of lines of business, in which similar lines of business are considered as a single line, collapsing the total number of lines, as in Berry-Stölzle et al. (2012). Although the choice of how to collapse the lines is somewhat subjective, the results for our analysis do not differ substantially based on the choice of diversification measure. In this paper, we report the results based on 24 business lines to facilitate comparison with more recent research. While not reported here, we also conducted robustness tests using a multi-line dummy as in Liebenberg and Sommer (2008).
} 
approximately 0.62. Paired $t$-tests for differences in means showed the decline in BLDIV to be significant at the $1 \%$ level..$^{9}$

[Insert Figure 1 Here]

When broken out by terciles of firm size, as depicted in Figure 2, the larger and more diversified firms experienced smaller changes in diversification than the less diversified firms over this period, but all three groups reduced product line diversification. Again, average GEODIV was virtually unchanged for each of the three firm size categories as shown in Figure 3.

[Insert Figure 2 Here]

[Insert Figure 3 Here]

Widespread Adoption of Enterprise Risk Management

Coinciding with the decline in diversification among $\mathrm{P} \& \mathrm{C}$ insurers, there has been increased interest in the adoption of ERM. This is not unique to insurers, but adoption rates are much higher among these firms than in other industries (Deloitte, 2011; RIMS, 2013). Although the motivations for this trend may be different by firm, regulatory pressure, technological advances in risk monitoring and measurement, and perceived value effects are all possible explanations.

To assist outside stakeholders and regulatory authorities in assessing risk management quality as a component of broader assessments of credit quality and capital adequacy, rating agencies have begun to assess ERM as well. For example, as one of the eight components of its financial strength rating for insurers (S\&P 2013b), Standard and Poor's rates each insurer's ERM program as: Excellent, Strong, Adequate, or Weak. This rating, which was first implemented in 2006, is based on an in-depth analysis of the firm's risk culture, processes for addressing current and future risk exposures, quality of risk modeling, and strategic integration. As evident from detailed rating agency documentation, the ERM quality ratings specifically consider the risk and reward tradeoffs in the firm's

\footnotetext{
${ }^{9}$ To see the economic significance of the decline in diversification, consider the following example. A firm with 70 percent of its business in one line of business and the remainder evenly split between five other lines of business has BLDIV equal to 0.5. A firm with only two lines of business, split 70 percent/30 percent has a BLDIV equal to 0.42 .
} 
diversification decisions 10 This provides further motivation for our hypothesis that a high quality ERM program (as assessed by S\&P's rating), combined with the optimized diversification strategies, may lead to improved firm performance and/or value.

Beginning in 2009, the Adequate category was split into three sub-levels: Adequate, Adequate with Strong Risk Controls, and Adequate with Positive Trend (S\&P, 2010a). In 2013, the Excellent category was renamed as Very Strong and the Adequate with Positive Trend category was eliminated (S\&P 2013a). Figure 4 illustrates the most recent distribution of these ratings for all P\&C insurers evaluated by Standard \& Poor's Ratings Services in 2013. Detailed definitions for each of these rating categories are provided in Appendix.

\section{[Insert Figure 4 Here]}

The number of insurers receiving ERM quality ratings has increased over time and the rated $\mathrm{P} \& \mathrm{C}$ insurers now represent more than half of the industry by market capitalization and nearly two-thirds by direct premiums written and net total assets. An even larger proportion of publicly-traded insurers (about $75 \%$ by premiums written and total assets) receive ERM quality ratings. The vast majority of firms receive a rating of Adequate. Comparing 2012 and 2013, a smaller proportion of firms were ranked as Weak and Excellent in 2013. Interestingly, P\&C insurers have a greater percentage of scores above Adequate than do life insurers. S\&P suggests that this is mainly because of life insurers' greater exposure to asset and market/interest rate-related risks, the longer time horizon for their risks, and the difficulties inherent in managing those risks especially in the post-financial crisis economic environment ${ }^{11}$

S\&P's ERM rating is also closely related to its widely-recognized financial strength rating for insurers. The financial strength rating is S\&P's assessment of the insurer's financial soundness and ability to meet ongoing obligations to its policyholders (S\&P, 2013b). Maintaining excellent financial strength ratings is important for insurers to attract and retain customers and to meet scrutiny from regulators and investors. Because insurers' liabilities are primarily obligations to policyholders rather than interest-bearing debt, the

\footnotetext{
${ }^{10}$ For example, in its explanation of 2013 ERM quality ratings, S\&P specifies that P\&C insurers with high ERM ratings will have "coordination across different business lines, geographies..." (S\&P, 2013a, p.24), "incentive structure ... tied to the portfolio-based performance targets that balance risk and rewards," (S\&P, 2013a, p.27), "frequent and thorough analysis of concentration," (S\&P, 2013a, p.25), and will "manage risks with an enterprise view, taking into consideration correlation and diversification." (S\&P, 2013a, p.8).

${ }^{11}$ Bajtelsmit, Villupurum and Wang (2015) discuss these issues more fully and show empirically that life insurers are more sensitive to downside risk.
} 
financial strength rating is considered to be as important as the general credit rating for these firms.

Table 1 delineates the S\&P ERM Quality Ratings for firms in each of the Financial Strength Rating categories ${ }^{12}$ and illustrates the positive relation between these two variables. While only a small percentage of insurers (about 15\%) received a financial strength rating during this sample period, over $80 \%$ of those with an ERM rating received a financial strength rating as well. We can also clearly see a positive relation between these two ratings. For example, all the AAA-rated firms have an ERM rating of either Strong or Excellent, and no insurer with a financial strength rating above an $\mathrm{A}+$ has a Weak ERM rating. Similarly, no insurer below a BBB+ rating has a Strong or Excellent ERM Quality Rating. However, it is also worth noting that the Financial Strength Rating would not be an appropriate proxy for ERM quality because there is still significant heterogeneity of the ERM ratings for firms with the same Financial Strength Rating, and vice versa.

[Insert Table 1 Here]

\section{The ERM-Diversification-Performance Relationship}

As discussed in the earlier sections, ERM may add value to a P\&C insurer by helping it better trade off the costs and benefits of geographic and product line diversification. Although diversification can offer synergies and scope economies, managing a more diverse enterprise may be more costly due to agency and coordination costs. Firms with well-functioning ERM programs may be better at managing these costs, resulting in improved performance relative to other similar firms in their industry. Given that previous studies have generally found more diversified firms to suffer a value discount, the purpose of this research is to evaluate the effects of ERM on financial performance in light of observed diversification strategies, while controlling for the effect of firm characteristics. We therefore run models of the general theoretical form:

$$
\begin{aligned}
& \text { Performance }=f(\text { ERM quality, diversification, } \\
& \qquad E R M \text { quality } \times \text { diversification } \mid \text { firm characteristics })
\end{aligned}
$$

Performance is alternatively measured as Return on Assets (ROA) and Tobin's Q to capture both the accounting-based performance and the market value assessment. ROA is measured as Net Income/Book Value of Assets and Tobin's Q is the (Market Value of

\footnotetext{
${ }^{12}$ Consistent with empirical studies in the credit rating and other finance literature, a larger numeric value of the financial strength rating variable indicates a lower quality of rating.
} 
Equity + Book Value of Liabilities)/Book Value of Assets. The Tobin's Q specification is only used for publicly-traded firms that derive most of their revenue from $\mathrm{P} \& \mathrm{C}$ insurance premiums and where market data is available. Although some studies have alternatively used Return on Equity (ROE) as a measure of performance, it is more difficult to compare across publicly-traded and private firms and thus we do not use it in this study.13

Based on the prior literature, we expect that, in addition to ERM-quality and diversification, firm financial performance will depend on size, capital structure, group affiliation, ownership characteristics, and risk 14 We discuss the construction of these variables and their expected relationship with the performance/value variable in more detail in the next section.

Sample and Data Description

The sample consists of all U.S. P\&C insurance companies for which S\&P ERM quality ratings are available, for the period from 2006 to 2013. The analysis is at the group level, with the unit of observation being the group or unaffiliated firm. 15 Although our sample firms may also write business in life and health lines, a firm is designated as a $\mathrm{P} \& \mathrm{C}$ insurer if they have reported to the NAIC as a P\&C insurer. After limiting the sample to groups and unaffiliated firms with positive premiums and ERM quality ratings, the final sample includes 76 unique firms ${ }^{16}$ (66 groups and 10 unaffiliated; 51 publiclytraded and 25 private firms) and a total of 467 firm-year observations. All publicly-traded firms are insurance groups. The ERM-rated P\&C firms in our sample account for 60.6 percent of direct premiums written during this period and 76.7 percent of direct premiums written by publicly-traded firms. Stock price data are from the Center for Research in Securities Prices (CRSP), and firm financial data are from the SNL Financial database and COMPUSTAT.

\footnotetext{
${ }^{13}$ Note that, as a component of the ERM assessment, S\&P measures a company's ability to optimize its risk profile by delivering less volatile operating performance. ROA is a better measure of operating performance for companies with longer-tailed liabilities.

${ }^{14}$ See Liebenberg and Sommer (2008), Elango, Ma and Pope (2008), Hoyt and Liebenberg (2011) for detailed discussion related to these control variables.

${ }^{15} \mathrm{~S} \& \mathrm{P}$ assigns a group ERM score because the scope of their analysis is the whole enterprise. Group members that are "core", "highly strategic", or "strategically important", such that their processes are integrated into the group ERM processes will all receive the same score. Other group members may receive a stand-alone ERM score, but their ERM deficiencies are factored into the ERM score of the group. (S\&P, 2013a)

${ }^{16} \mathrm{~A}$ total of 212 insurance and reinsurance firms have received ERM quality ratings from S\&P during the sample period. There are $86 \mathrm{P} \& \mathrm{C}$ firms with matches in the SNL database. After removing observations with missing/negative net total assets and missing ROA, our final ERM sample includes 76 firms.
} 
The initial sample of publicly-traded insurers includes 51 unique firms and 340 observations. The ratings and statutory data are based on these firms' $\mathrm{P} \& \mathrm{C}$ insurance operations, whereas the Compustat Tobin's Q measure is based on group-level consolidated balance sheets that can include non-P\&C operations. For insurers that have substantial revenue from non-P\&C sources, the use of an ERM rating that is tied to the P\&C insurance operations only would potentially result in a bias against finding a significant ERM-value relation ${ }^{17} 18$ To remove potential bias created by firms that have non-P\&C revenue sources, we also create a truncated sample of publicly-traded firms including only those that have at least $70 \%$ of revenues from insurance premiums and at least $70 \%$ of premiums in $\mathrm{P} \& \mathrm{C}$ business lines ${ }^{19}$ This sample, which is used for the Tobin's $\mathrm{Q}$ analysis, consists of 28 firms and 159 observations.

The key variables of interest are measures of ERM quality and diversification. Business line diversification (BLDIV) and geographic diversification (GEODIV) are calculated using equations (1) and (2) over 24 lines of business and 57 geographies. As compared to ERM implementation variables that have been used in most previous studies, the S\&P ERM-quality rating described above offers several advantages. First, it is clearly superior to measures based on announcements such as appointment of a CRO or ERM adoption which are noisy measures and do not allow differentiation based on the quality of ERM processes. As discussed in the earlier sections, many benefits of ERM can only be achieved with an overall high quality implementation. Measuring this degree of quality is the primary goal of the S\&P ERM ratings. A simple indicator for ERM alone will not be able to provide such information. Second, the S\&P ERM quality rating provides a more precise measurement of quality and does not require subjective judgment of the researcher or an executive responding to a survey. The S\&P ERM rating is given by an independent third party, which makes it preferable to measures based on self-reported survey data. Possible criticisms include the number of firms currently being rated, the number of years of available data (2006-2013), the qualitative nature of many of the criteria from S\&P's perspective, and the potential for manipulation or collusion with evaluators. ${ }^{20}$ Neverthe-

\footnotetext{
${ }^{17}$ In results not reported here, estimation of Tobin's Q models for the full sample of publicly-traded P\&C insurers produced insignificant results for Tobin's Q, arguably due to this bias.

${ }^{18}$ This is not an issue with the ROA sample because the ROA analysis only uses financial data for ERM-rated firms that self-report as P\&C insurers to the NAIC, while the Tobin's Q measure is a proxy for the value of the holding company based on consolidated financial data from all members of a group, whether they are $\mathrm{P} \& \mathrm{C}$ insurers or not.

${ }^{19}$ We thank an anonymous reviewer for this valuable suggestion.

${ }^{20}$ Fair and accurate ratings arguably play an important role in the financial system. As with other types of financial ratings, there can exist the potential for conflict of interest when agencies receive fees from rated companies. For example, S\&P receives compensation for its ratings and analytic services, normally
} 
less, it is our opinion that the S\&P ERM quality rating is a better proxy for the quality of ERM implementation and will be useful for many research purposes, particularly as more years of rating data become available and the rated firms represent an increasing share of the P\&C industry.

In our analysis, the S\&P ERM ratings are used to create dummy variables for ERM Quality. Because relatively few firms receive Strong and Excellent/Very Strong ratings, we collapse those groups into one category for analysis (ERM QUALITY=E/S). Similarly, we collapse the Adequate sub-categories (after year 2010) into one (ERM QUALITY=A) for consistency with data from the previous years. The reference category is the Weak rating (ERM QUALITY=W) ${ }^{21}$

Figure 5 provides a graphical illustration of the relationship between the S\&P ERM rating and performance for the pooled sample of rated firms from 2006-2013. Consistent with our expectation that better quality implementation of ERM in insurance company organizations may be value-enhancing, we see a clearly monotonic relationship between ERM rating and performance for both performance measures. Firms with an Excellent/Strong ERM rating, on average, perform better than the firms with Weak ERM ratings.

\section{[Insert Figure 5 here]}

While these univariate results suggest a positive relationship between effective ERM strategy and performance, other factors, such as diversification and firm characteristics, are expected to play a role. Explanations for the significant diversification discount found in other studies often focus on the complexities inherent in large organizations, agency costs, and internal capital market inefficiencies. These costs may be sufficiently large to offset the advantages of scope economies and risk reduction. ${ }^{22}$ To better understand

from issuers or underwriters of securities or from obligors, and therefore could be subject to agency problems. However, evidence suggests that reputational concerns discipline rating agency behavior. Becker and Milbourn (2008, 2011) and Smith and Walter (2002) find evidence that in a competitive environment for rating agencies, the provision of quality ratings is at least partially sustained by the reputational concerns of the rating agencies.

${ }^{21}$ For the two stage least squares analysis, we use numerical scores for each rating category in the first stage estimation. Some studies have attempted to more finely categorize by ERM quality. For example, Baxter et al. (2013) create a rating of 1 to 6 from the original S\&P ratings. With only three years of ratings, this creates some small sample issues which are somewhat alleviated by the inclusion of a range of financial services firms in their estimation. Further, there is no reason to believe that the value effect from going from one category of Adequate to a better level of adequate is the same as that of going from Weak to Adequate or Adequate to Strong.

${ }^{22}$ Although the finance literature has often identified the relatedness of business segments as a potential problem for diversified firms, limiting our sample to the P\&C industry removes much of that concern. 
the combined effects of ERM and diversification, we control for business line (BLDIV) and geographic (GEODIV) diversification when examining the impact of ERM on insurer performance.

Table 2 summarizes and defines all variables used in our analysis and Table 3 compares the summary descriptive statistics by ERM-rating status, for U.S. P\&C insurance companies in the SNL database over the period 2006 to 2013. The additional control variables in our model include SIZE, measured as the log of admitted assets, CAPITALIZATION, measured as policyholder surplus divided by admitted assets, whether the firm is a member of a group (GROUP $=1)$, form of organization (STOCK $=1$ ), the percent of total premiums written in commercial lines (\%COMMERCIAL), the percent of total assets in stocks, mortgages, and real estate (\%RISKYASSETS), and the percent of premiums written in the life \& health sector $(\% \mathrm{~L} / \mathrm{H})$.

\section{[Insert Table 2 Here] \\ [Insert Table 3 Here]}

Size has been shown to significantly affect performance, although studies have differed on the sign. To the extent that there are diseconomies of scale and unmonitored agency costs, we would expect to see reduced value for larger firms. However, larger insurers may have lower insolvency risk, better market penetration, customer loyalty, reduced earnings volatility, and efficiency of operations that may lead to positive value effects (Liebenberg and Sommer, 2008). Our analysis is at the group level and includes unaffiliated insurers. Groups may perform better relative to unaffiliated insurers because the ability to share capital across group members should increase performance (Schlütter and Gründl, 2012). But at the same time, internal capital markets may result in inefficient capital allocations such as cross-subsidization of poorly performing segments. Therefore, the expected total effect of GROUP is indeterminate. The expected effect of organizational form is ambiguous. Mutuals may have higher costs for managerial monitoring, but stock companies are exposed to owner-policyholder incentive conflicts. However, the benefits of access to capital markets by stock companies may offset the agency-related disadvantages of the stock form of ownership. Well-capitalized firms are expected to have better performance. Firms that invest more heavily in risky assets may perform better in the long run but also are subject to higher risk. Firms in highly competitive commercial lines are expected to have lower performance. Firms that write business in both the $\mathrm{P} \& \mathrm{C}$ and life-health sectors are expected to underperform firms that focus only on one of the two sectors (Hoyt and Trieschmann 1991). 
Additional variables used in the first stage of our two stage least squares (2SLS) model, but excluded in the second stage, include AGE of the insurer, FS RATING, and \%REINSURANCE. Consistent with Hoyt and Liebenberg (2011), we define reinsurance use as the ratio of reinsurance premium ceded to the sum of direct premium written and reinsurance premium assumed ${ }^{23}$ Summary statistics for these three variables are also included in Table 3. We discuss the choice of these variables and their validity as instrument variables in conjunction with the description of the 2SLS models in the next section.

The results of paired t-tests indicate that the ERM-rated sample is significantly younger, larger, and more diversified by both product line and geography. The ERMrated firms are much more likely to be in an insurance group and to be publicly-traded. Although the ERM-rated firms are less capitalized and use less reinsurance, the average financial strength rating is significantly higher. Interestingly, the univariate comparison shows that the rated firms exhibit higher performance than unrated firms on average in terms of the accounting-based ROA measure, although ROA is not a direct consideration in selecting the firms to rate or deriving the ratings. The market-value based Tobin's Q measure is non-distinguishable between the two samples. Similar and oftentimes larger differences in performance measures and firm characteristics are observed between the sub-sample of publicly-rated ERM-rated insurers used for the Tobin's Q analysis and the ERM-unrated firms. Based on the differences between rated and unrated firms, conclusions drawn from our analysis of the rated firms may not be generalizable to the whole industry.

\section{Empirical Results}

The effect of ERM quality on P\&C insurer performance is estimated using 2SLS to account for potential endogeneity. Our hypothesis is that ERM quality has a positive effect on performance, but it is possible that other variables jointly determine performance with the ERM quality rating. We estimate a linear model in the first stage and include all of the control variables from the second stage in order to ensure that the error term and the estimated ERM rating are uncorrelated. In the first stage, we estimate the ERM quality rating with a set of instruments that are expected to be associated with quality of the

\footnotetext{
${ }^{23}$ Theoretically reinsurance premium ceded (assumed) should equal to the sum of premium ceded to (assumed from) affiliates and premium ceded to (assumed from) non-affiliates. However, since our analysis is for insurance groups and non-affiliated insurers, premium ceded to (assumed from) affiliates should be zero and we only consider premium ceded to (assumed from) non-affiliates in our calculation.
} 
ERM program. The dependent variable in the first stage is the ERM Quality Rating (=1, 2 , or 3 ), where a higher number corresponds to a better rating, i.e., Weak $=1$, Adequate $=2$ and Strong/Excellent $=3$. We include AGE as a proxy for organizational complexity. Because complexity will add to the difficulties and costs in holistic risk management, we expect more complex firms to have a lower ERM quality rating. As discussed previously, we also expect that firms with better financial strength to have sufficient resources to invest in high quality risk management programs (Baxter, et al., 2013) and therefore expect a negative coefficient for the FS RATING variable (because a low rating indicates better financial strength). Lastly, we include \%REINSURANCE because of its importance to an insurer's ERM program. We expect that firms with greater usage of reinsurance will have a better ERM quality rating. We also include control variables that are in the second-stage regression: SIZE, CAPITALIZATION, GROUP, STOCK, GEODIV, \%COMMERCIAL, \%RISKYASSETS, and \%L/H. Note that the variables GROUP and STOCK are not included in the Tobin's Q regressions because all the firms included in those regressions are members of insurance groups and are stock companies.

\section{[Insert Table 4 here]}

The results of the first stage estimation of ERM QUALITY are provided in Panel A of Table $4{ }^{24}$ In both the ROA and Tobin's Q regressions, AGE and GEODIV, as proxies for organizational complexity, reduce the ERM rating, and the FS RATING variable has a negative sign, indicating that high quality ERM is associated with greater financial strength. \%REINSURANCE does not have a significant impact on the ERM rating. Most of the other control variables are not significant determinants of the ERM quality rating. ${ }^{25}$ The F-statistic from the first stage and the Hansen J test suggest that this combination of instruments satisfy the relevance and exclusion restriction requirements. The estimated ERM quality ratings from the first stage regression are then used as controls in the second stage performance regressions.

The results of the second stage of the 2SLS regressions are reported in Panel B of Table 4. The dependent variables are ROA and Tobin's Q. For more direct comparability with previous studies, we report the results for three versions of the model for each of

\footnotetext{
${ }^{24}$ The ERM sample contains 50 unique firms with both ERM and financial strength ratings for the ROA regressions and 28 firms for Tobin's Q regressions.

${ }^{25}$ The results reported for the first stage regression in Models (2) and (3), and those in Models (5) and (6) are the same because these two models only differ in the second stage. They also include an additional control variable BLDIV because this variable is included in the second stage regression for these two models.
} 
the performance measures: including only the estimated ERM QUALITY rating from the first stage (Models 1 and 4), adding the BLDIV variable (Models 2 and 5), and adding the BLDIV $\times$ ERM QUALITY interaction term (Models 3 and 6). To account for the panel structure of our sample, we estimate the models with year fixed effects and adjust the standard errors for firm-level clustering (Petersen 2009; Thompson 2011) ${ }^{26}$ We include control variables for firm characteristics that have been used in previous studies of insurance company performance (Hoyt and Liebenberg, 2011; Liebenberg and Sommer, 2008; Elango, Ma, and Pope, 2008) ${ }^{27}$ including SIZE, CAPITALIZATION, GEODIV, GROUP, STOCK, \% COMMERCIAL, \% RISKYASSETS, and \%L/H. Again, note that the variables GROUP and STOCK are not relevant for the Tobin's Q regressions.

The results of the 2SLS analysis show that ERM QUALITY has a positive and significant effect on both ROA and Tobin's Q in all of the second stage regressions. Note that, by limiting the Tobin's Q sample to publicly-traded firms that derive at least 70 percent of revenue from insurance premiums and at least 70 percent of premium revenue from $\mathrm{P} \& \mathrm{C}$ lines, the sample size is much smaller than that used in the ROA analysis. Although the results are largely consistent with the ROA results, they may not be broadly applicable to a larger cross-section of publicly-traded insurers.

More interestingly, we find that diversification also has a significant and positive effect on ROA when ERM quality is taken into account and is an insignificant factor for Tobin's Q. This suggests that with a high quality ERM program, diversification can be a viable performance-enhancing strategy for insurers rather than a negative factor as has been shown to be true, on average, for $\mathrm{P} \& \mathrm{C}$ insurers. Most of the control variables have the expected effect on performance or are insignificant. In general, we find that firms that are better capitalized and those affiliated with a group have higher ROA. Stock firms do not perform as well as mutuals, and firms in highly competitive commercial lines also have lower performance. Firms that have a significant portion of their business in the life and health sector also tend to perform better.

Our results show that the combined effects of a high quality ERM program and a

\footnotetext{
${ }^{26}$ The results of a Hausman test suggest that fixed effects is a better specification than random effects. Liebenberg and Sommer (2008) argue that year fixed effects were not advised with their sample because the key explanatory variable, a dummy for multiline firms, did not exhibit sufficient variation over time. The diversification measures used in this study exhibit much greater time variation. Because of the potential overlap between the ERM quality variable and the firm fixed effects, any ERM-specific effects may be masked by the firm fixed effects. This is an empirical problem similar to one encountered in the credit rating literature. We follow the literature (Kuang and Qin 2013) and do not include firm fixed effects but adjust the standard errors for firm-level clustering.

${ }^{27}$ Note that we can only include a limited set of control variables because of the small sample size. We have selected the ones that are shown to be most important in the previous literature.
} 
diversification strategy are positive on firm performance, as measured by ROA or Tobin's Q. These results are largely consistent with ERM studies using an ERM implementation indicator (e.g., Hoyt and Liebenberg 2011) as previously discussed. This is also consistent with earlier studies that have considered the effect of ERM quality ratings for shorter sample periods, such as Baxter et al. (2013), who find the ERM quality rating to have a positive effect on ROA and Tobin's Q for the period 2006-2008, McShane, Nair, and Rustambeokov (2011) who find a positive relationship between ERM rating and Tobin's Q for 2008, and Pooser (2012) for the period 2009-2010 (ROA only). However, our results are inconsistent with Lin, Wen, and Yu (2012), who find ERM to result in a discount to firms' performance measured by ROA or Tobin's Q in their single year study.

To further investigate the joint performance effects of diversification and ERM, we also run a pooled ordinary least squares (OLS) regression where ERM quality is measured using categorical dummy variables for Adequate (ERM QUALITY = A) and Excellent/Strong $($ ERM QUALITY $=\mathrm{E} / \mathrm{S})$. The omitted category is Weak. This categorical specification allows us to investigate the economic significance of our results and also allows more direct comparison to results of the previous literature on the diversification-performance relationship. Again, the OLS regression is for the sample of P\&C groups and unaffiliated firms with non-negative premiums and assets and S\&P ERM quality ratings for the years 2006-2013. The ROA estimation includes the full sample, and the Tobin's Q estimations include the publicly-traded firms that derive at least $70 \%$ of revenues from insurance premiums and at least $70 \%$ of premiums from P\&C business. As a first step, we examine the diversification-performance relationship for our sample without the ERM control variable. These results are reported as Models 1 and 5 in Table 5. Firm and year fixed effects are controlled for and the robust standard errors are adjusted for firm- and year-level clustering. Consistent with the prior literature, we find a highly significant diversification discount to firm's performance, when measured by ROA (Model 1). However, we do not find a significant diversification discount for Tobin's Q (Model 5). This is likely due to the smaller degree of variation in diversification in the sample of publicly-traded insurers and the much smaller sample size.

\section{[Insert Table 5 Here]}

We next examine our main hypotheses by including both ERM QUALITY and diversification (BLDIV) as independent variables, controlling for various firm characteristics, and for year fixed effects. For each of the measures of performance (ROA and Tobin's Q), we first estimate a model controlling only for ERM QUALITY and firm characteristics 
(Models 2 and 6). In Models 3 and 7 we include the ERM QUALITY dummies and diversification (BLDIV), and in Models 4 and 8 , we add an interaction term BLDIV $\times$ ERM QUALITY 28

Consistent with the 2SLS results, the OLS results show that ERM quality has a strong positive impact on both ROA and Tobin's Q. As compared to firms that receive "Weak" ERM quality ratings, firms rated as "Excellent/Strong" and "Adequate" both have significantly higher performance. When both ERM quality and business line diversification are included in the ROA models, the ERM coefficient is lower but still positive and significant. In contrast to previous studies that suggest a negative performance effect for business line diversification, we find that business line diversification has a strong positive effect on ROA. As previously reported in this paper, $\mathrm{P} \& \mathrm{C}$ insurers have been steadily reducing their product line diversification over the last decade. This may, in fact, be the observed results of joint consideration of the diversification strategy and ERM implementation, thus lessening the previously documented diversification discount effects. After controlling for the interactions between the ERM ratings and BLDIV, we find that the combined marginal effects of both diversification and ERM quality on ROA are still positive. The results for Tobin's Q are largely consistent with the ROA results discussed above. Again, these results can be subject to the sample limitations discussed previously.

Our results also reveal the nuanced relationship between the ERM quality, product line diversification, and firm performance. With everything else equal, the combined marginal effect of ERM quality and diversification on ROA for a less diversified firm (BLDIV $=0.2$ ) and Adequate ERM quality is $4.908 \%$ whereas the effect for a similar but more diversified firm (BLDIV $=0.8$ ) with Adequate ERM is $7.084 \% .29$ In comparison, for firms with Excellent/Strong ERM quality, the estimated effect on ROA is $7.205 \%$ for the less diversified firm and $6.232 \%$ for more diversified firms ${ }^{30}$ Although the combined effect of ERM quality and diversification is positive for all four hypothetical firms, the economic

\footnotetext{
${ }^{28}$ For robustness, we have also run the 2 SLS and OLS regressions using either the risk-adjusted ROA as the dependent variable, defined as ROA divided by the rolling 3-year standard deviation of ROA, or adding the 3-year standard deviations of ROA as a control for risk. The results are largely the same as our main results presented in the paper.

${ }^{29}$ Compared to the reference category of firms with Weak ERM, the combined marginal effect of ERM QUALITY and BLDIV on ROA can be estimated as [4.183 $\times($ ERM QUALITY $=\mathrm{A})]+[7.529 \times(\mathrm{ERM}$ $\mathrm{QUALITY}=\mathrm{E} / \mathrm{S})]+[8.077 \times \mathrm{BLDIV}]-[4.451 \times \mathrm{BLDIV} \times(\mathrm{ERM} \mathrm{QUALITY}=\mathrm{A})]-[9.698 \times \mathrm{BLDIV} \times$ $(\mathrm{ERM}$ QUALITY $=\mathrm{E} / \mathrm{S})]$. Thus, the effect for the less diversified hypothetical firm with Adequate ERM quality is calculated as $4.183+(8.077 \times 0.2)-(4.451 \times 0.2)=4.908$ and the effect for the more diversified hypothetical firm is calculated as $4.183+(8.077 \times 0.8)-(4.451 \times 0.8)=7.084$.

${ }^{30}$ The effect on the Excellent/Strong ERM quality and less diversified firm's ROA is $7.529+(8.077 \times$ $0.2)-(9.698 \times 0.2)=7.205$ and the effect for the more diversified firm is $7.529+(8.077 \times 0.8)-(9.698 \times 0.8)=$ 6.232 .
} 
benefit of having an Excellent/Strong ERM program is greater for the less diversified firms ${ }^{31}$ This may reflect the additional cost of implementing excellent ERM in the more complex system of a diversified firm 32

\section{Summary and Conclusions}

This study uses a sample of P\&C insurers with S\&P ERM quality ratings from 2006 to 2013 to investigate the independent and combined effects of ERM and diversification on $\mathrm{P} \& \mathrm{C}$ insurer performance. In contrast to previous studies that document significant product line and geographic diversification discounts relative to more focused competitors, we find that the combined effect of product line diversification and ERM quality on both ROA and Tobin's Q is positive relative to those with weak-rated ERM programs. For the firms in our sample, geographic diversification is not a significant factor determining ROA, but may have a negative effect on Tobin's Q.

With increasing regulatory pressure to adopt and implement enterprise-wide risk management programs, this research is both timely and important for large financial institutions. Better understanding of the impact of ERM will inform the development of rating criteria, reporting requirements, and managerial decision-making. Although most insurance companies have begun to implement ERM at some level, their ERM programs are multi-faceted and differ widely from firm to firm. Assessment of the value of such programs requires more detailed understanding of the components. Our study adds to the growing body of research on the value of ERM by providing a unique perspective to assess potential ERM outcomes for firms with different diversification strategies.

There are four acknowledged limitations to this study. First, our sample is limited to $\mathrm{P} \& \mathrm{C}$ insurers that have received an ERM quality rating from the S\&P. These firms, on average, are more likely to be large, publicly-traded group insurers. Therefore, the results and insights are not necessarily generalizable to the entire industry. Limiting the analysis to $\mathrm{P} \& \mathrm{C}$ insurers is an intentional choice to avoid previously-documented issues related to industry-specific differences. However, because the sample represents more than

\footnotetext{
${ }^{31}$ Similar quantitative effects are found for Tobin's Q but should be interpreted with caution due to the stronger sample limitations.

${ }^{32}$ As a robustness check, we also investigate whether the ERM-diversification-performance relationship was affected by the financial crisis. By adding a financial crisis dummy (and omitting the year fixed effects) in our regressions, we find that our main results are not substantially different and firm performance is significantly worse during the financial crisis period. To conserve space, we do not report these results in the paper but they are available upon request from the authors.
} 
$60 \%$ of all $\mathrm{P} \& \mathrm{C}$ insurers based on direct premium written, these results are economically significant. Second, the Tobin's Q results are based on an even smaller subset of firms and are therefore only applicable to large publicly-traded $\mathrm{P} \& \mathrm{C}$ insurance groups which derive most revenue from P\&C business. Third, we implicitly assume that the S\&P ERM quality rating is a proxy for the true quality of a firm's ERM program. Because the ERM quality rating is a component of a broader assessment of credit rating and capital adequacy, it is possible that the analysts more narrowly focus on aspects of ERM that are relevant to credit risk. Documentation available from S\&P suggests that their assessment covers a wide range of risk management issues, but closer examination of the ERM rating criteria and the relationship between the ERM rating and the financial strength ratings may be an avenue for future research. Lastly, while the Hausman test of exogeneity suggests only minor endogeneity of diversification concern in our sample, it could potentially be a bigger concern if future research enlarges the sample to include other insurers such as life and health firms. In such cases, a two-dimensional treatment effects model may be appropriate. 


\section{References}

Ai, J., P. L. Brockett, W. W. Cooper, and L. Golden, 2012, Enterprise Risk Management Through Strategic Allocation of Capital, Journal of Risk and Insurance, 79(1): 29-56.

Ai, J., P. L. Brockett, and T. Wang, 2015. Optimal Enterprise Risk Management and Decision Making with Shared and Dependent Risks, Journal of Risk and Insurance, Forthcoming.

Bajtelsmit, V. L., and R. Bouzouita, 1998, Market Structure and Performance in Private Passenger Automobile Insurance, Journal of Risk and Insurance, 65(3): 503-514.

Bajtelsmit, V. L., S.V. Villupuram, T. Wang, 2015. Life Insurer Cost of Equity with Asymmetric Risk Factors, Financial Review, 50(3): 435-457

Baxter, R., J. C. Bedard, R. Hotash, and A. Yezegel, 2013, Enterprise Risk Management Program Quality: Determinants, Value Relevance, and the Financial Crisis, Contemporary Accounting Research, 30(4): 1264-1295.

Beasley, M. S., B. Branson, and B. Hancock, 2012, Report on the Current State of Enterprise Risk Oversight (Raleigh, NC: ERM Initiative at North Carolina State University).

Beasley, M. S., R. Clune, and D. R. Hermanson, 2005, Enterprise Risk Management: An Empirical Analysis of Factors Associated with the Extent of Implementation, Journal of Accounting and Public Policy, 24(6): 521-531.

Beasley, M. S., D. P. Pagach, and R. Warr, 2008, The Information Conveyed in Hiring Announcements of Senior Executives Overseeing Enterprise-Wide Risk Management Processes, Journal of Accounting, Auditing, and Finance, 23(3): 311-332.

Becker, B., and T. Milbourn, 2008, Reputation and Competition: Evidence From the Credit Rating Industry. Harvard Business School.

Becker, B., and T. Milbourn, 2011, How Did Increased Competition Affect Credit Ratings? Journal of Financial Economics, 101(3): 493-514.

Berger, A. N., J. D. Cummins, M. A. Weiss, and H. Zi, 2000, Conglomeration Versus Strategic Focus: Evidence from the Insurance Industry, Journal of Financial Intermediation, 9(4): 323-362.

Berry-Stölzle, T., A. Liebenberg, J. Ruhland, and D. Sommer, 2012, Determinants of Corporate Diversification: Evidence from the Property-Liability Insurance Industry, Journal of Risk and Insurance, 79(2): 381-413.

Berry-Stölzle, T., R. Hoyt, and S. Wende, 2013, Capital Market Development, Competition, Property Rights, and the Value of Insurer Product-Line Diversification: A Cross-Country Analysis, Journal of Risk and Insurance, 80(2):423-459.

Berry-Stölzle, T., and J. Xu, 2013, Enterprise Risk Management and the Cost of Capital, Working Paper, Terry College of Business, University of Georgia.

Brown, E. F., 2013, Will the Federal Insurance Office Improve Insurance Regulation? University of Cincinnati Law Review, 81(2):1-49.

Cummins, J.D., and M. Weiss, 2014, Analyzing Firm Performance in the Insurance Industry Using Frontier Efficiency and Productivity Methods, in Handbook of Insurance, $2^{\text {nd }}$ Edition (New York: Springer).

Cummins, J.D., and X. Xie, 2009, Market Values and Efficiency in US Insurer Acquisitions and Divestitures, Managerial Finance, 35(2): 128-155. 
Deloitte, 2011, Global Risk Management Survey, $7^{\text {th }}$ ed. Navigating in a Changed World, available at www.iia.nl/SiteFiles/Global\%20Risk\%20Management\%20Survey-7.pdf.

Deloitte, 2012, Aftershock: Adjusting to the New World of Risk Management, available at http://www2.deloitte.com/us/en/pages/governance-risk-and-compliance/articles/ aftershock.html.

Doherty, N., 2000, Integrated Risk Management: Techniques and Strategies for Managing Corporate Risk (New York: McGraw-Hill Companies).

Eckles, D., R. Hoyt, and S. Miller, 2014, The Impact of Enterprise Risk Management on the Marginal Cost of Reducing Risk: Evidence from the Insurance Industry, Journal of Banking and Finance, 43: 247-261.

Elango, B., Y. Ma, and N. Pope, 2008, An Investigation into the Diversification-Performance Relationship in the U.S. Property-Liability Insurance Industry, Journal of Risk and Insurance, 75(3): 567-591.

Farrell, M. and R. Gallagher, 2014, The Valuation Implications of Enterprise Risk Management, Journal of Risk and Insurance, 82 (3): 625-657.

Federal Insurance Office, 2013, Annual Report on the Insurance Industry, (Washington, D.C.: U.S. Department of the Treasury).

Froot, K. A., D. S. Scharfstein, and J. C. Stein, 1993, Risk Management: Coordinating Corporate Investment and Financing Policies, Journal of Finance, 48(5): 1629-1658.

Gamba, A., and A. J. Triantis, 2013, Corporate Risk Management: Integrating Liquidity, Hedging, and Operating Policies, Management Science, 60(1): 246-264.

Gatzert, N. and M. Martin, 2013, Determinants and Value of Enterprise Risk Management: Empirical Evidence from the Literature, Working Paper, Friedrich Alexander University of Erlangen-Nürnberg.

Gordon, L. A., M. P. Loeb, and C. Tseng, 2009, Enterprise Risk Management and Firm Performance: A Contingency Perspective, Journal of Accounting and Public Policy, 28(4): 301-27.

Grace, M. F., J. T. Leverty, R. D. Phillips, P. Shimpi, 2015, The Value of Investing in Enterprise Risk Management, Journal of Risk and Insurance, 82(2): 289-316.

Hoyt, R., and A. Liebenberg, 2011, The Value of Enterprise Risk Management, Journal of Risk and Insurance, 78(4): 795-822.

Hoyt, R., and J. S. Trieschmann, 1991, Risk/Return Relationships for Life-Health, PropertyLiability, and Diversified Insurers, The Journal of Risk and Insurance 58(2): 322-330.

Jensen, M. C., and W. H. Meckling, 1976, Theory of the Firm: Managerial Behavior, Agency Costs and Ownership Structure, Journal of Financial Economics 3: 305-360.

Jones, G. R., and C. W. L. Hill, 1988, Transaction Cost Analysis of Strategy-Structure Choice, Strategic Management Journal, 9(2): 159-172.

Kleffner, A. E., R. B. Lee, and B. McGannon, 2003, The Effect of Corporate Governance on the Use of Enterprise Risk Management: Evidence from Canada, Risk Management and Insurance Review, 6(1): 53-73.

Kraus, V., and O. Lehner, 2012, The Nexus of Enterprise Risk Management and Value Creation: A Systematic Literature Review, ACRN Journal of Finance and Risk Perspectives, 1(1): 91-163.

Kuang, Y. F., and B. Qin, 2013, Credit Ratings and CEO Risk-Taking Incentives, Contemporary Accounting Research, 30(4): 1524-1559. 
Laeven, L., and R. Levine, 2007, Is There a Diversification Discount in Financial Conglomerates? Journal of Financial Economics, 85(2): 311-367.

Leverty, J. T., and M. F. Grace, 2010, The Robustness of Output Measures in PropertyLiability Insurance Efficiency Studies, Journal of Banking and Finance, 34(7): 1510-1524.

Liebenberg, A., and R. E. Hoyt, 2003, Determinants of Enterprise Risk Management: Evidence from the Appointment of Chief Risk Officers, Risk Management and Insurance Review, 6(1): 37-52.

Liebenberg, A., and D. Sommer, 2008, Effects of Corporate Diversification: Evidence from the Property-Liability Insurance Industry, Journal of Risk and Insurance, 75(4): 893-919.

Lin, Y., M. M. Wen, and J. Yu, 2012, Enterprise Risk Management: Strategic Antecedents, Risk Integration and Performance, North American Actuarial Journal, 16(1): 1-28.

MacMinn, R. D., 1987, Insurance and Corporate Risk Management, Journal of Risk and Insurance, 54(4): 658-677.

McShane, M. K., A. Nair, E. Rustambekov, 2011, Does Enterprise Risk Management Increase Firm Value, Journal of Accounting, Auditing, and Finance, 26(4): 641-658.

Meulbroek, L. K., 2002, A Senior Manager's Guide to Integrated Risk Management, Journal of Applied Corporate Finance, 14(4): 56-70.

Modigliani, F., and M. H. Miller, 1963, Corporate Income Taxes and the Cost of Capital: A Correction, American Economic Review, 53(3): 433-443.

Myers, S. C., and Read, J. A. Jr., 2001, Capital Allocation for Insurance Companies, Journal of Risk and Insurance, 68(4): 545-580.

NAIC, 2014, NAIC Own Risk and Solvency Assessment (ORSA) Guidance Manual, Washington, DC: National Association of Insurance Commissioners and the Center for Insurance Policy and Research, available at www.naic.org/store/free/ORSA_manual.pdf.

Nayyar, P. R., 1992, On the Measurement of Corporate Diversification Strategy: Evidence From Large U.S. Service Firms, Strategic Management Journal, 13(3): 219-235.

Nocco, B. W., and R. M. Stulz, 2006, Enterprise Risk Management: Theory and Practice, Journal of Applied Corporate Finance, 18(4): 8-20.

Pagach, D., and R. Warr, 2011, The Characteristics of Firms that Hire Chief Risk Officers, Journal of Risk and Insurance, 78(1): 185-211.

Petersen, M. A., 2009, Estimating Standard Errors in Finance Panel Data Sets: Comparing Approaches, Review of Financial Studies, 22(1): 435-480.

Pooser, D., 2012, An Empirical Examination of The Interrelations Of Risks And The Firm's Relation With Enterprise Risk Management, Doctoral Dissertation, Florida State University.

Powell, L. S., and D. W. Sommer, 2007, Internal Versus External Capital Markets in the Insurance Industry: The Role of Reinsurance, Journal of Financial Services Research, 31(2-3): 173-188.

RIMS, 2013, RIMS Benchmark Survey on Enterprise Risk Management, available at www. rims.org.

Santalo, J., and M. Becerra, 2008, Competition from Specialized Firms and the DiversificationPerformance Linkage, Journal of Finance, 63(2): 851-883.

Schlütter and Gründl, 2012, Who Benefits from Building Insurance Groups? A Welfare Analysis of Optimal Group Management, The Geneva Papers on Risk and Insurance Issues and Practice, 37: 571-593. 
Shim, J., 2011, Mergers \& Acquisitions, Diversification and Performance in the U.S. PropertyLiability Insurance Industry, Journal of Financial Services Research, 39(3):119-144.

Smith, R. C., and I. Walter, 2002, Rating Agencies: Is There An Agency Issue? (pp. 289-318, Springer US.)

Smithson, C., and B. J. Simkins, 2005, Does Risk Management Add Value? Journal of Applied Corporate Finance, 17(3): 8-17.

S\&P, 2009, GEICO Insurance Group, Standard \& Poor's Ratings Services (Oct. 22, 2009), available at www.standardandpoors.com/ratingsdirect.

S\&P, 2010a, Expanded Definition of Adequate Classification in Enterprise Risk Management Scores, Standard \& Poor's Ratings Services (Jan. 28, 2010), available at www. standardandpoors.com/ratingsdirect.

S\&P, 2010b, Enterprise Risk Management Continues To Show Its Value For North American And Bermudan Insurers, Standard \& Poor's Ratings Services (Feb. 1, 2010), available at www . standardandpoors.com/ratingsdirect.

S\&P, 2011, USAA Insurance Group and Operating Subsidiaries, Standard \& Poor's Global Credit Portal, Ratings Direct (Nov.1, 2011), available at www.standardandpoors.com/ ratingsdirect.

S\&P, 2013a, Enterprise Risk Management, Standard \& Poor's Ratings Services (May 7, 2013), available at www. standardandpoors . com/ratingsdirect.

S\&P, 2013b, Insurers: Rating Methodology Standard \& Poor's Ratings Services (May 7, 2013), available at www.standardandpoors . com/ratingsdirect.

S\&P, 2013c, Process Improvements And Regulation Drive ERM Of North American And Bermudian Insurers Forward, Standard \& Poor's Ratings Services (April 18, 2013), available at www.standardandpoors . com/ratingsdirect.

Thompson, S. B., 2011, Simple Formulas for Standard Errors that Cluster by Both Firm and Time, Journal of Financial Economics, 99(1): 1-10.

Tombs, J. W., and R. E. Hoyt, 1994, The Effect of Product Line Focus on Insurer Stock Returns. Proceedings of the International Insurance Association Annual Meeting 331-337. 


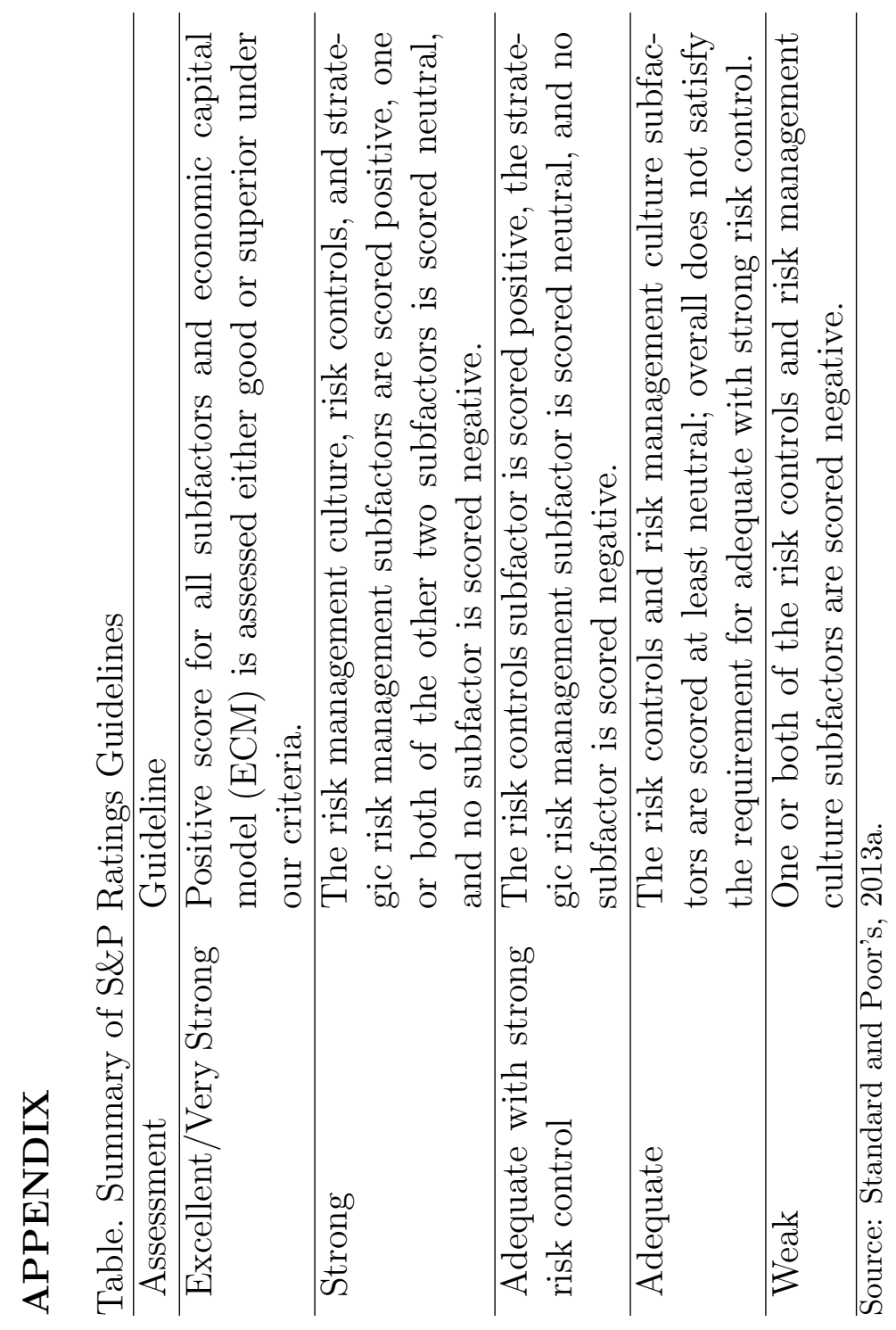




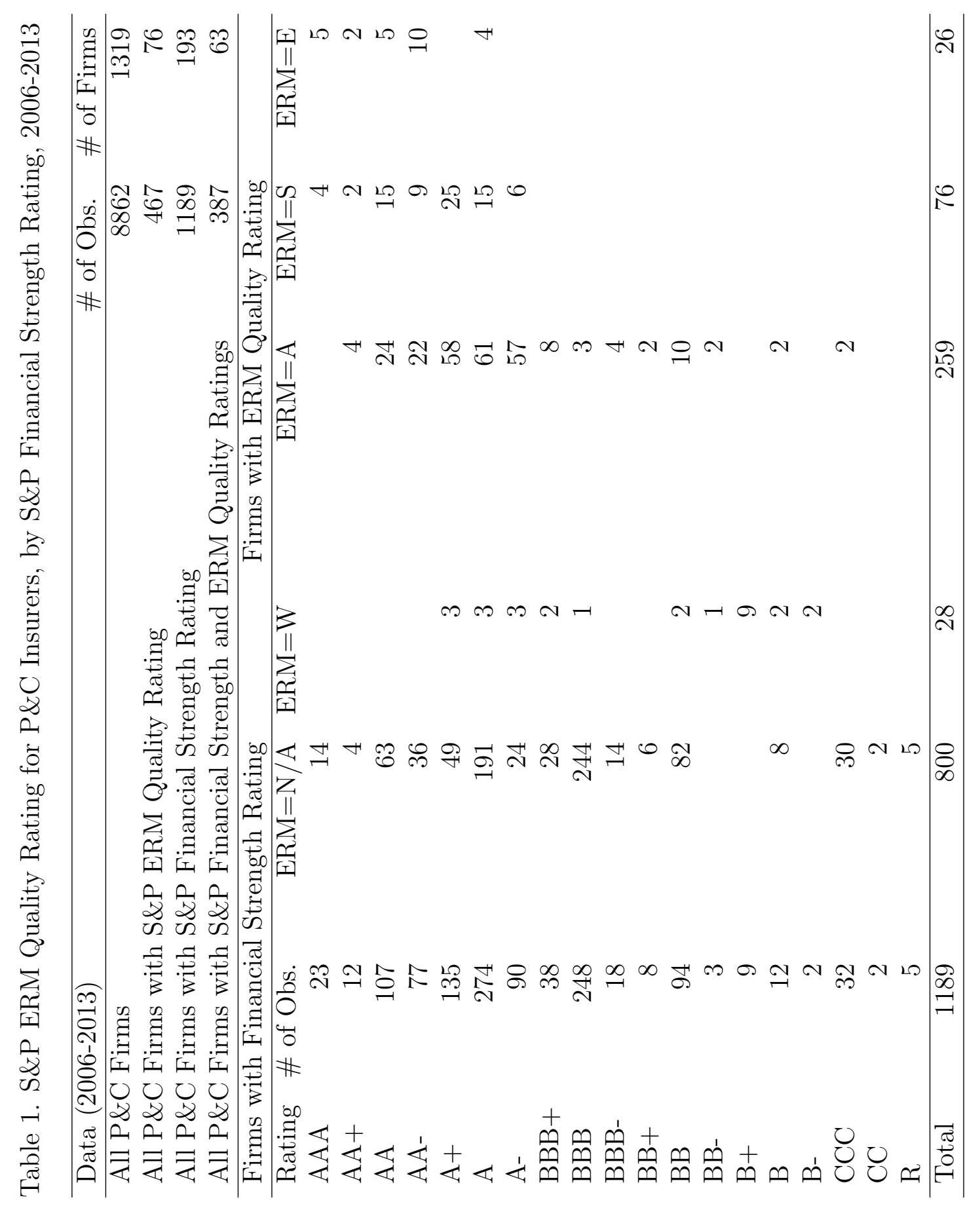




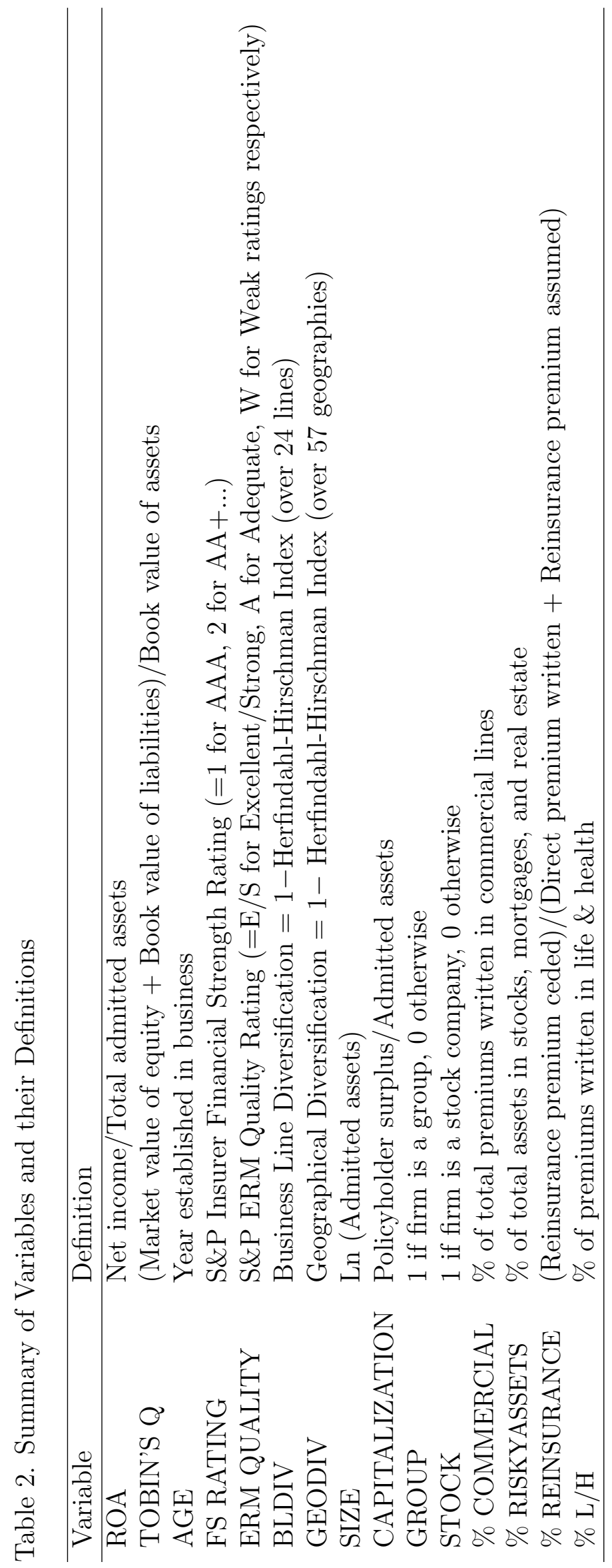




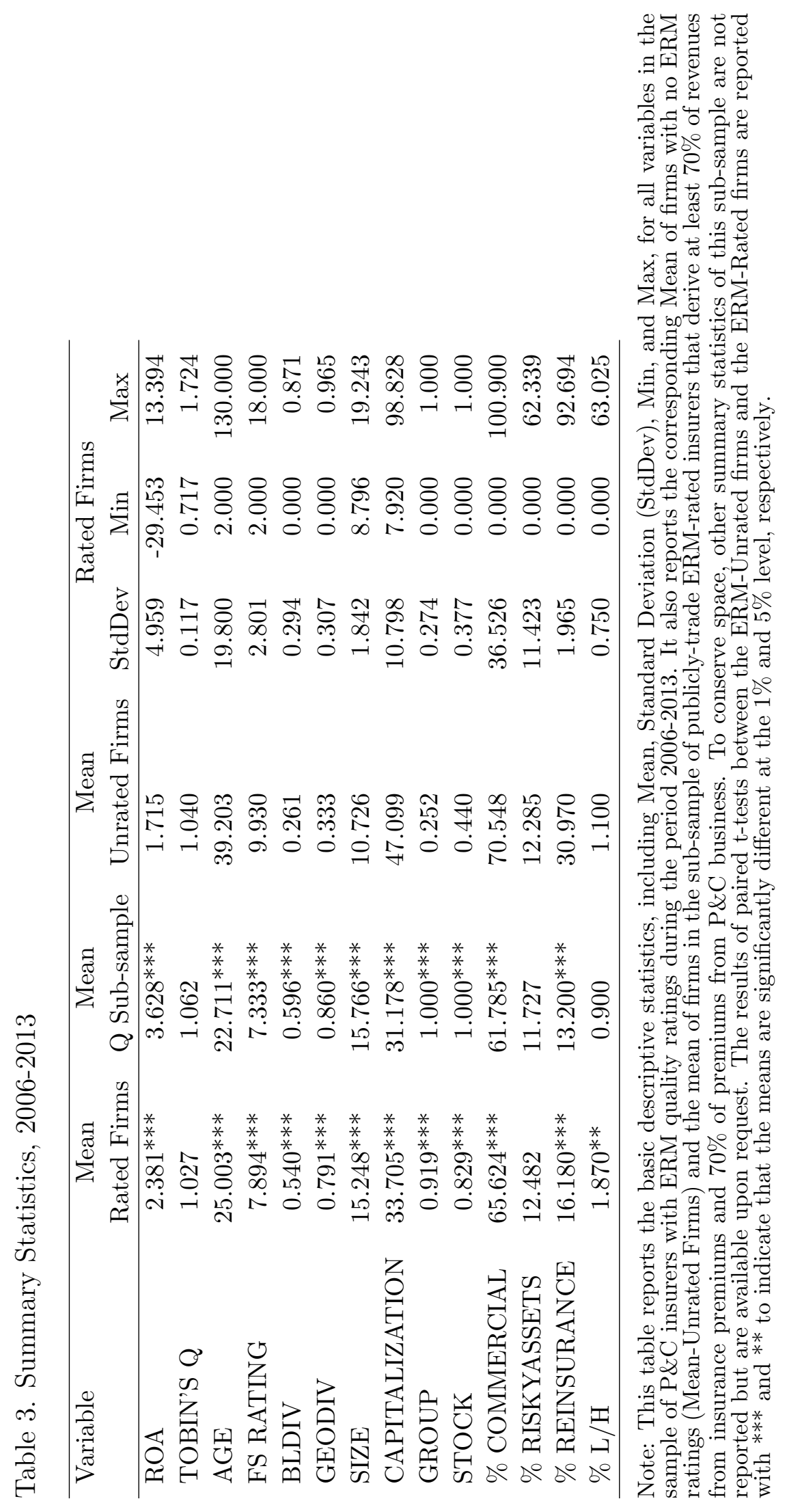




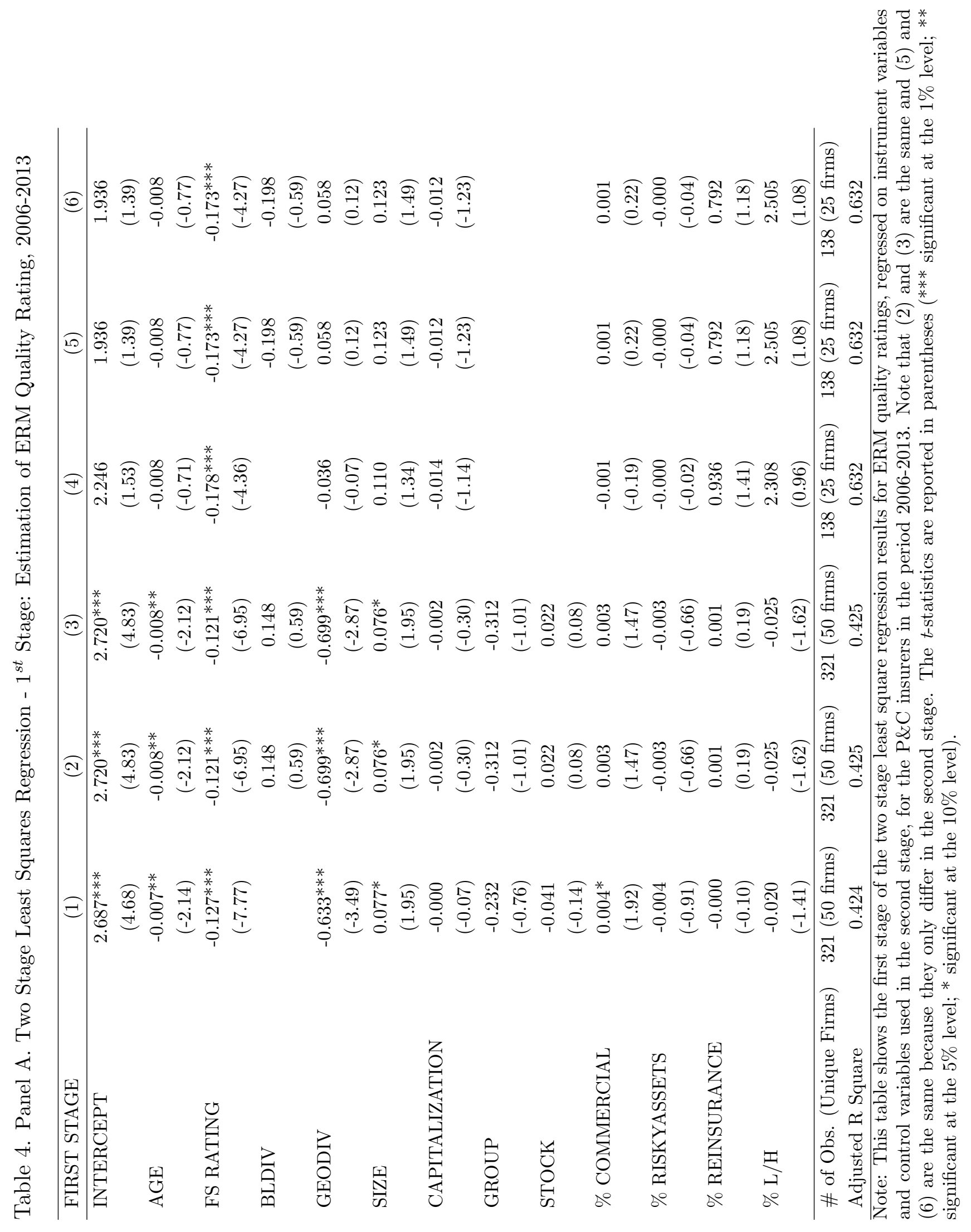




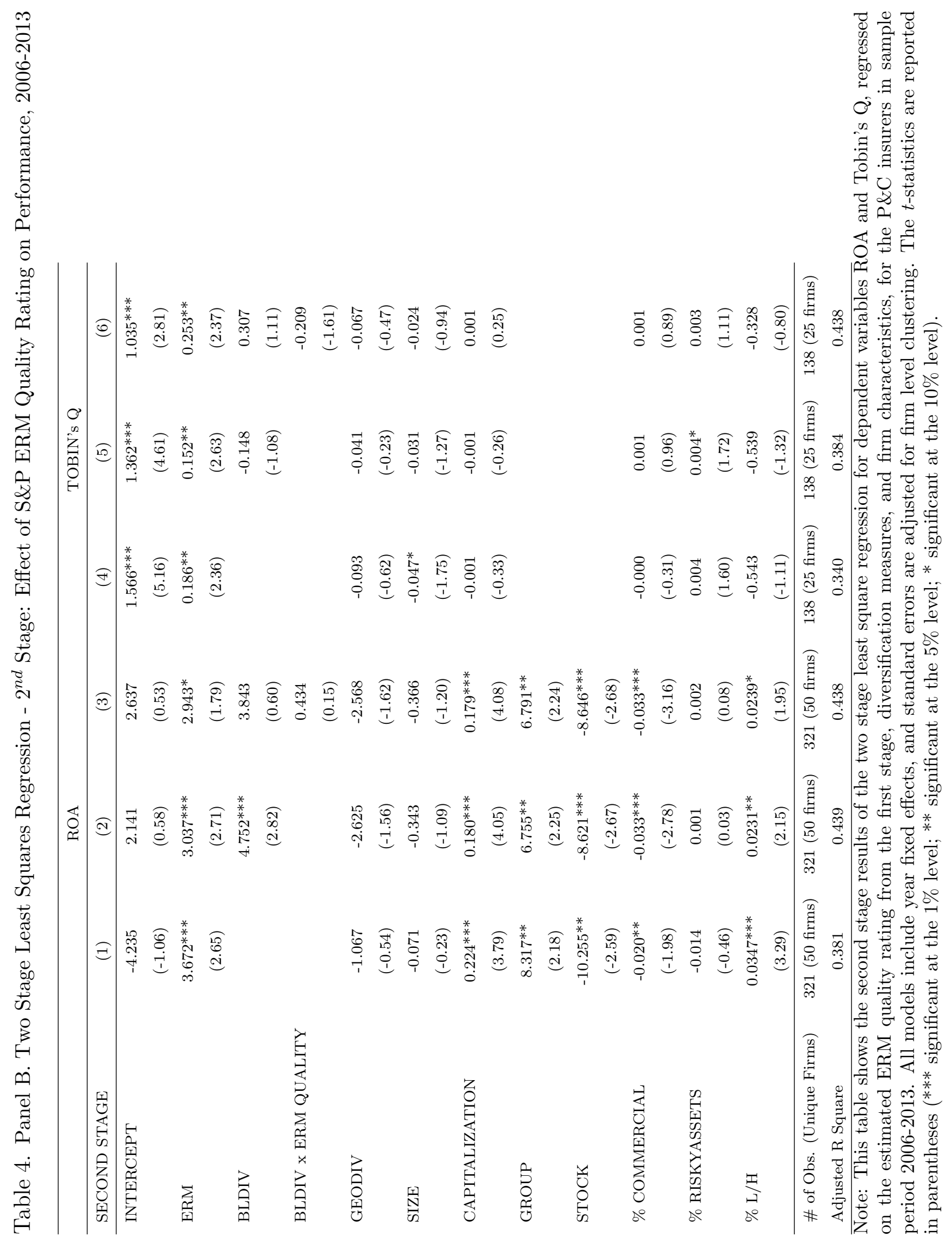




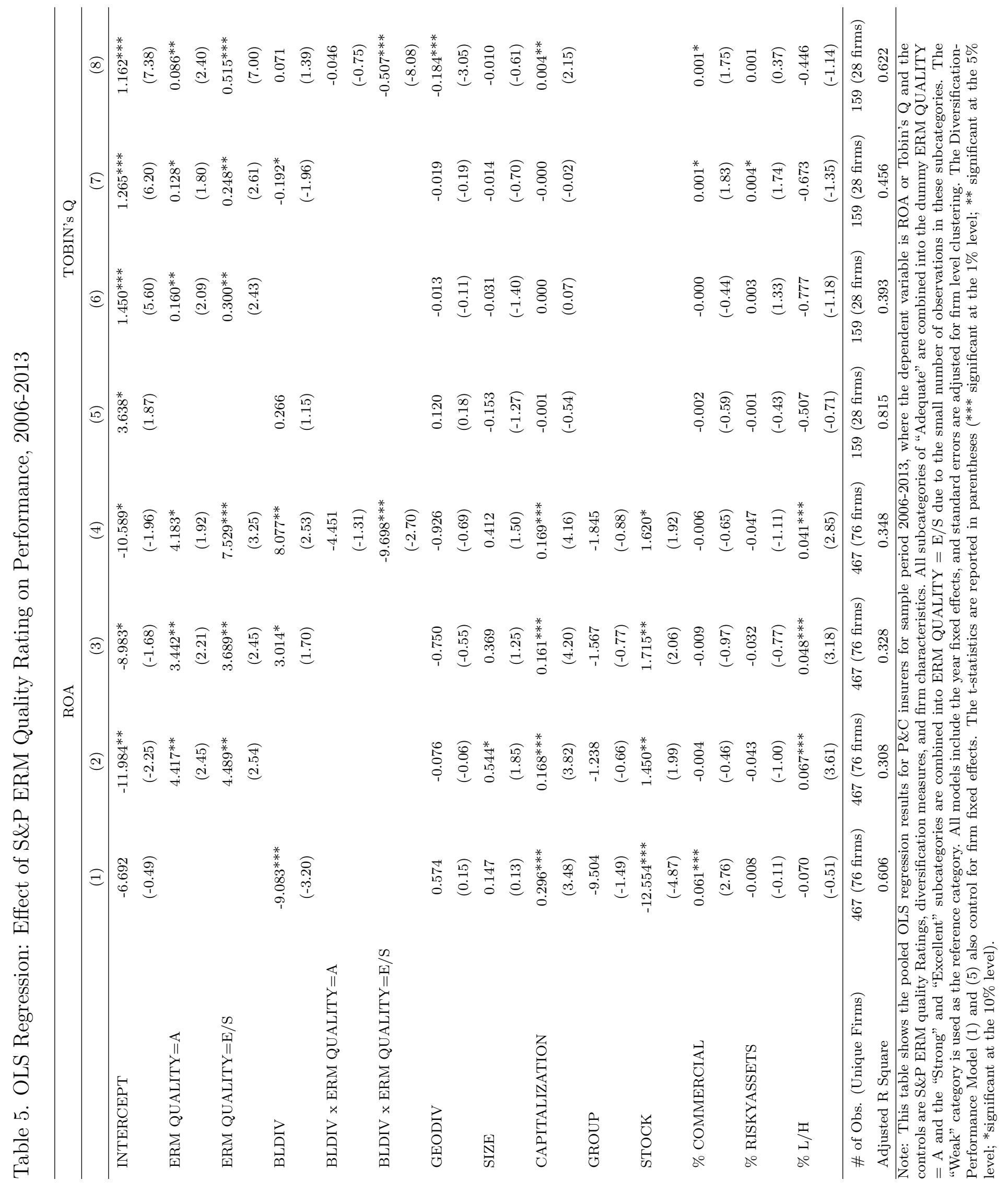


Figure 1. Business Line and Geographic Diversification, 2001-2013

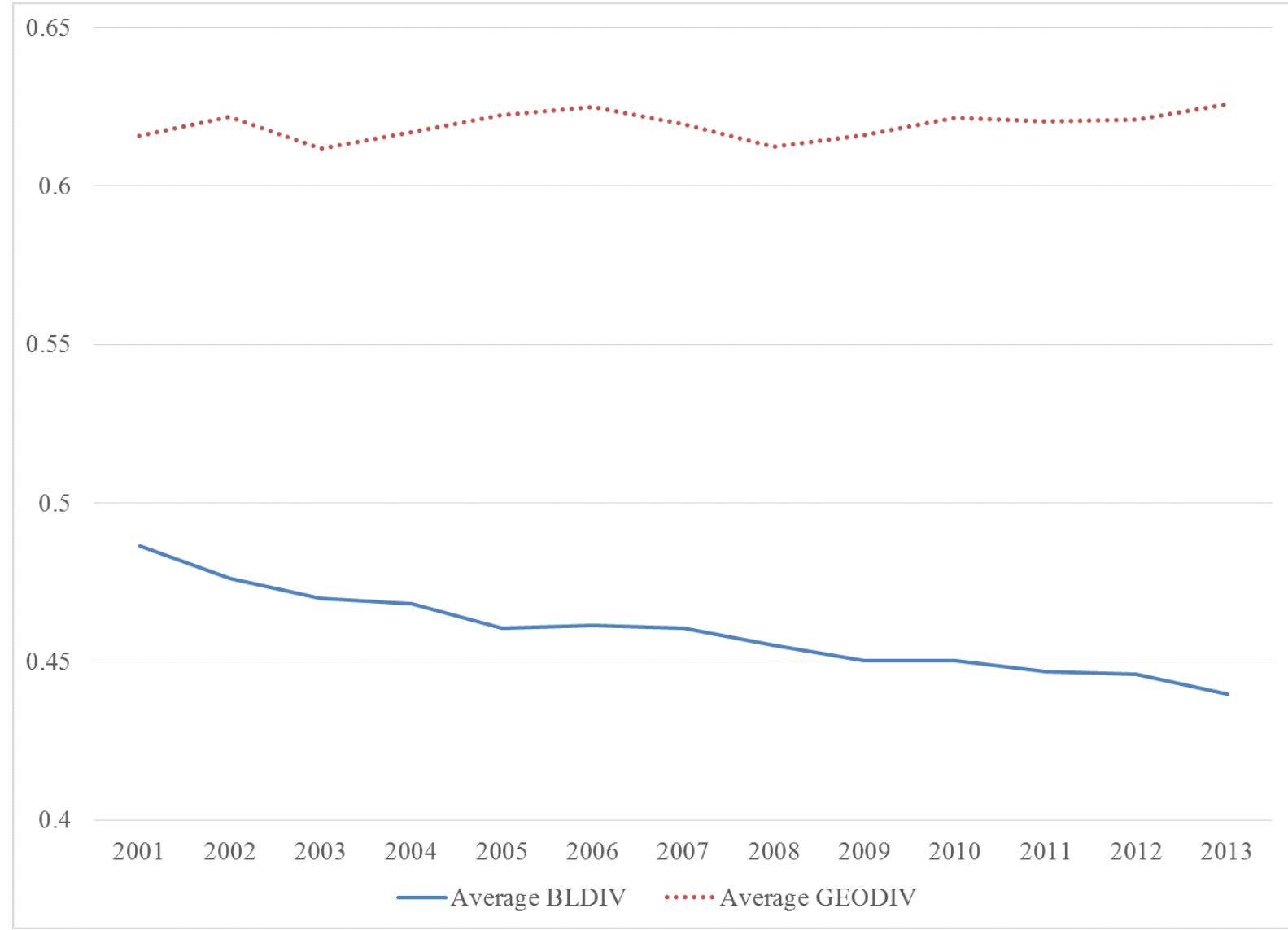

Note: This figure shows the trends in average BLDIV and GEODIV from 2001 to 2013. BLDIV measures an insurer's business line diversification and is the complement of the Herndahl-Hirschman Index calculated using direct premiums written across all business lines. GEODIV measures geographic diversification and is the complement of the Herndahl-Hirshman Index calculated using direct premiums written over all states. 
Figure 2. Business Line Diversification by Tercile of Firm Size, 2001-2013

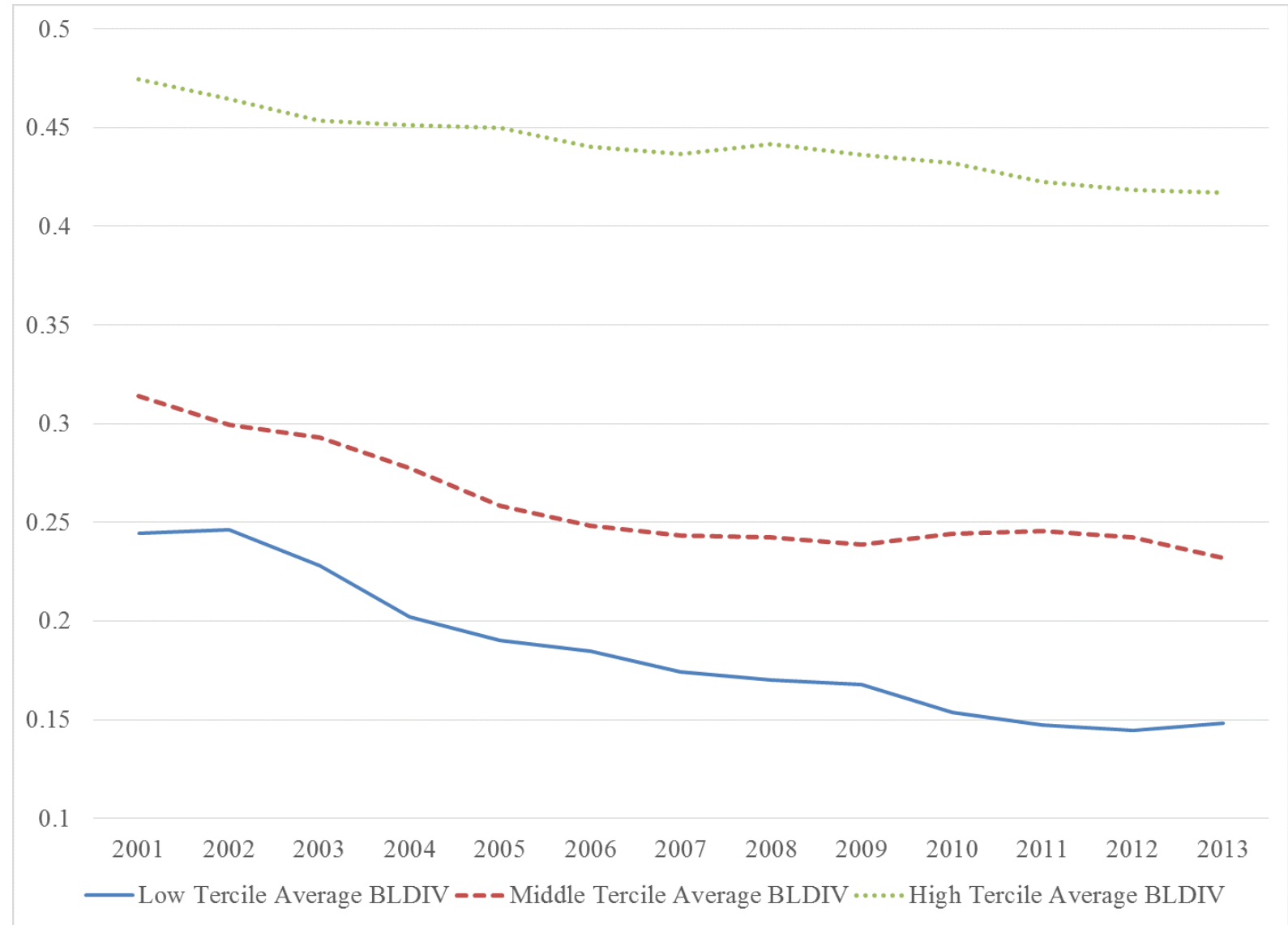

Note: This figure shows the trend in average BLDIV for each tercile of firm size from 2001-2013. BLDIV measures an insurer's business line diversification and is the complement of the Herndahl-Hirschman Index calculated using direct premiums written across all business lines. 
Figure 3. Geographic Diversification by Tercile of Firm Size, 2001-2013

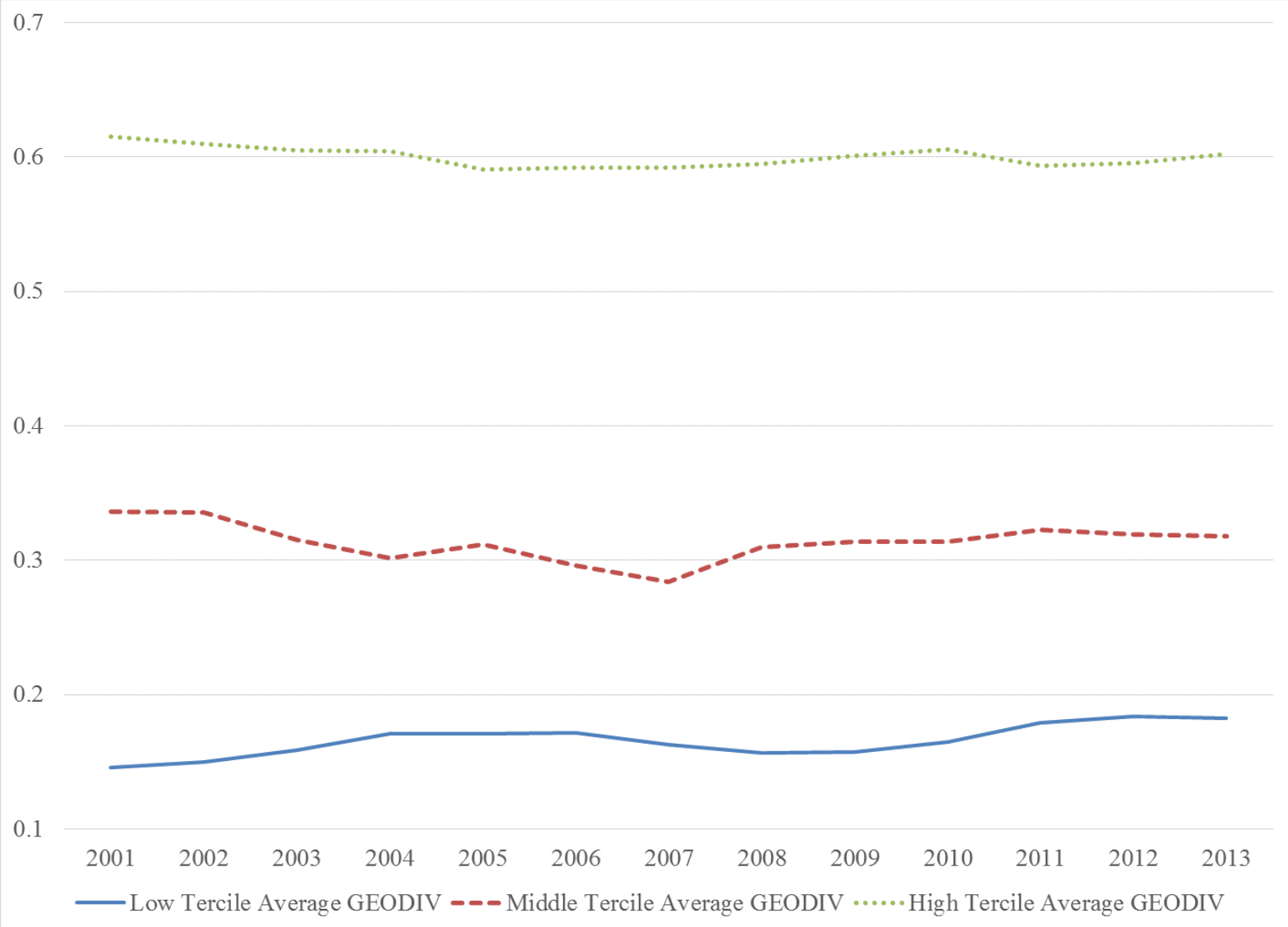

Note: This figure shows the trend in average GEODIV for each tercile of firm size from 2001-2013. GEODIV measures geographic diversification and is the complement of the Herndahl-Hirschman Index calculated using direct premiums written over all states. 
Figure 4. Distribution of S\&P ERM Quality Ratings for all Rated P\&C Insurance Firms

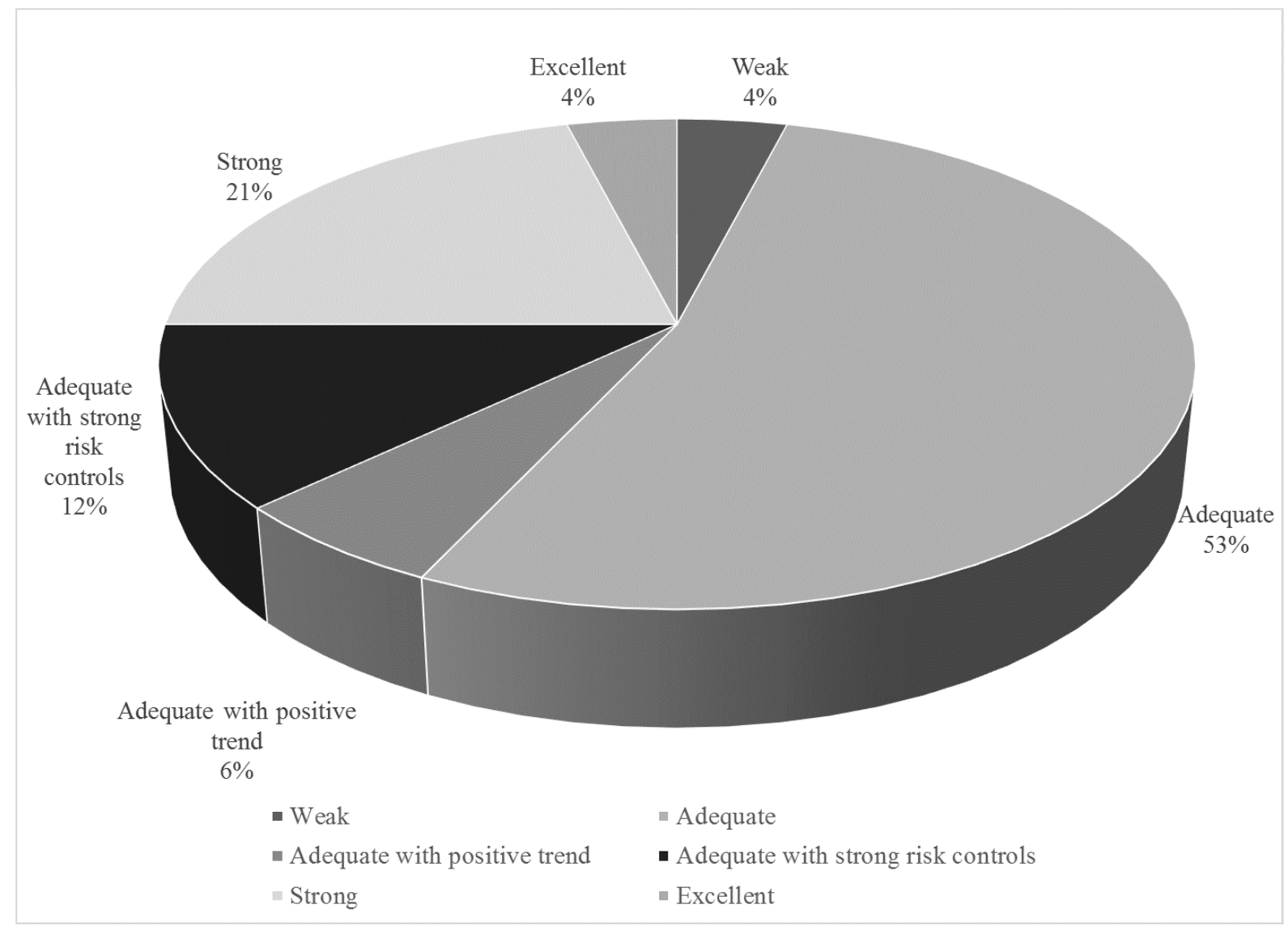

Source: Standard and Poor's, 2013c. 
Figure 5. Performance by ERM Quality Rating, Sample of Firms with S\&P ERM Quality Ratings, 2006-2013

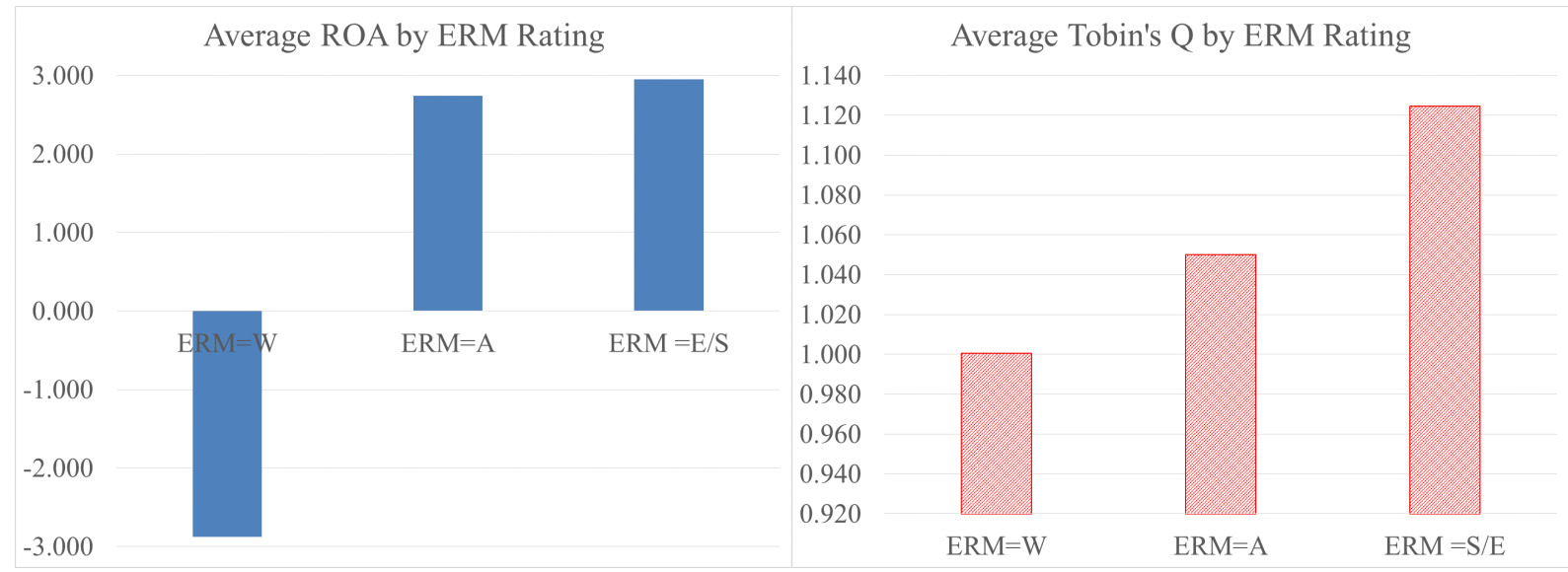

Note: Panel A illustrates the relationship between Average ROA and ERM Quality Rating for rated firms in the pooled cross-sectional time series. The average ROA is $-2.875 \%$ for ERM Quality Rating=Weak (W), 2.741\% for ERM Quality Rating=Adequate (A) and 2.947\% for ERM Quality Rating=Excellent/Strong (E/S). Panel B illustrates the relationship between Average Tobin's Q and ERM Quality Rating in our sample. The average Tobin's Q is 1.001 for ERM Quality Rating=Weak (W), 1.050 for ERM Quality Rating=Adequate (A), and 1.125 for ERM Quality Rating=Excellent/Strong (E/S). 